\title{
F-16XL Hybrid Reynolds-Averaged Navier-Stokes/Large Eddy Simulation on Unstructured Grids
}

\author{
Michael A. Park ${ }^{\star}$, Khaled S. Abdol-Hamid ${ }^{\dagger}$, Alaa Elmiligui ${ }^{\ddagger}$ \\ NASA Langley Research Center, Hampton, VA 23681
}

\section{Abstract}

The Cranked Arrow Wing Aerodynamics Program, International (CAWAPI) investigation is continued with the FUN3D and USM3D flow solvers to fuse flight test, wind tunnel test, and simulation of swept wing aerodynamic features. Simulations of a low speed, high angle of attack condition are compared. Detached Eddy Simulation (DES), Modified Delayed Detached Eddy Simulation (MDDES), and the Spalart-Allmaras (SA) RANS model. Isosurfaces of Q criterion show the development of coherent primary and secondary vortices on the upper surface of the wing that spiral, burst, and commingle. Mean DES and MDDES pressures better predict the flight test measurements than SA model predictions, especially on the outer wing section. The USM3D simulations predicted many sharp tones in volume point pressure spectra with low broadband noise and The FUN3D simulations predicted more broadband noise with weaker tones. Spectra of the volume points near the outer wing leading-edge was primarily broadband for both codes. Time-averaged forces are very similar between FUN3D simulations and and similar between USM3D simulations, but FUN3D predicts slightly higher lift and lower drag than USM3D. There is more variation in the pitching moment predictions. Spectra of the unsteady forces and moment are mostly broadband for FUN3D and tonal for USM3D simulations.

\section{Introduction}

\begin{abstract}
The Cranked-Arrow Wing Aerodynamics Project (CAWAP) was established to document upper-surface flow physics at high-lift and transonic test conditions and to characterize the stability and control of the F-16XL aircraft. [1] Ship one, F-16XL-1, provides a unique opportunity to fuse flight test, wind tunnel test, and computational fluid dynamics (CFD) to understand the aerodynamic features of swept wings. [2] The High-Speed Research (HSR) program identified a need to improve understanding of swept-wing aerodynamic performance. [1] High lift prediction during takeoff and landing continues to be a critical element of viable quiet supersonic aircraft concepts. [3,4] Studying the high lift performance of the cranked-arrow wing planform has been a focus for supersonic transports for decades [5] and this study addresses a flow condition that is important for understanding pitch-up. [6] Low-boom supersonic transport concepts recently developed include highly swept [7] and cranked-arrow planforms, [8] which is the focus of this study.
\end{abstract}

\footnotetext{
${ }^{*}$ Research Scientist, Computational AeroSciences Branch, AIAA Senior Member.

$\dagger$ Research Aerospace Engineer, Configuration Aerodynamics Branch, AIAA Associate Fellow.

${ }^{*}$ Research Aerospace Engineer, Configuration Aerodynamics Branch, AIAA Senior Member.
} 
The original CAWAP project grew into an international collaboration. the Cranked Arrow Wing Aerodynamics Program, International (CAWAPI). [1] An assessment at the competition of CAWAPI [9] indicated that "Overall, it can be said that the technology readiness of computational fluid dynamics simulation technology for the study of vehicle performance has matured since 2001, such that it can be used today with a reasonable level of confidence for complex configurations." However, simulations at two Flight Conditions (FC), numbered 25 and 70, did not compare as well to flight measurements as the other FCs near the center of the Mach/angle of attack flight envelope. Test point FC 25 is low speed and high angle of attack and exhibits unsteady vortex burst phenomenon. Test point FC 70 is a high speed case dominated by vortex-shock interaction. With the exception of two papers, $[10,11]$ analysis was performed with steady Reynolds-averaged Navier-Stokes (RANS) and Euler methods for CAWAPI.

A subsequent program [12] (CAWAPI-2) targeted additional FCs near FC 25 and FC 70. These nearby conditions were chosen primarily to help establish trends in the measured pressures associated with the vortex and shock structures near FC 25 and 70. [12]

Sensitivities to aeroelasticity and control surface deflection were noted. [13] Finer grids and improved physics simulation due to advanced turbulence models and unsteady hybrid RANS/Large Eddy Simulation (HRLES) resulted in improved predictions of flight test measurements. [13] This study continues the CAWAPI-2 investigation with two simulation tools and focuses on FC 25 and HRLES methods. Continued evaluation and development of HRLES models is a recommendation of the CFD Vision 2030 Study, "The use of CFD in the aerospace design process is severely limited by the inability to accurately and reliably predict turbulent flows with significant regions of separation. . . Hybrid RANS-LES and wall-modeled LES offer the best prospects for overcoming this obstacle although significant modeling issues remain to be addressed here as well." [14] The study recommendation suggests this work is critical for the development of future aerospace design methods.

Previous CAWAPI and CAWAPI-2 investigations used USM3D (Unstructured Mesh ThreeDimensional), which is also applied in this study. Lamar and Abdol-Hamid [15] compared surface pressures and boundary layer profiles computed with three RANS models to flight test measurements. Elmiligui et al. [16] applied grid adaptation to these same three RANS models. Elmiligui, Abdol-Hamid, and Parlette [17] applied unsteady RANS and HRLES. This study expands the HRLES study to include FUN3D (Fully Unstructured Navier-Stokes Three-Dimensional) and examine the fluctuating pressure frequency spectra to better understand the application of HRLES to a cranked-arrow wing planform.

\section{Flight Condition 25 and Instrumentation}

This report focuses solely on FC 25, a subsonic high angle-of-attack case. The freestream flow conditions are Mach $M=0.242,19.84^{\circ}$ angle of attack, and $32.22 \times 10^{6}$ Reynolds number based on the reference chord length. The freestream conditions are the U.S. Standard Atmosphere [18] at 10,000 ft. pressure altitude. Propulsion boundary conditions are obtained from Obara and Lamar. [1] The FUN3D [19, 20] and USM3D [21] code nondimensionalize the propulsion boundary conditions with freestream conditions to produce the ratios listed in Table 1. 
A three-view drawing of F-16XL-1 is shown in Fig. 1. The cranked-arrow planform (more sweep on the inner wing than the outer wing) is clearly evident. The geometry of the configuration is summarized in Table 2. Dummy wing tip missiles and rails are attached to each wing tip. There is an actuator pod and air dam located at the wing trailing-edge break, which is slightly inboard of the wing leading-edge break. Boelens et al. [22] describe the geometry modifications used to create a water-tight geometry for grid generation and state that the control surfaces are not deflected. Details of the F-16XL-1 instrumentation is available in Lamar et al. [2] and the pressure measurement locations are shown in Fig. 2. The heavy black lines denote the location of pressure belts of 0.028 in. inner diameter tubing used to measure surface pressure. These pressure belts are placed at constant butt lines (BL) and have orifices at common fuselage stations (FS), which allows comparison to simulation in either plane. Due to the curvature of the upper wing surface, water line (WL) varies between orifices. No measurement uncertainties or unsteady pressure measurements are available from the flight tests.

\section{Numerical Approach}

The focus of this report is applying the HRLES capabilities of USM3D and FUN3D. First, these flow solvers and the HRLES methods are described. Then details on the time step and grids are provided.

\section{A. USM3D}

The USM3D [23] code is a cell-centered finite volume flow solver (the solution is stored at tetrahedra centers). The spatial discretization in nominally second-order and it is part of TetrUSS (Tetrahedral Unstructured Software System). [24] The USM3D code uses advanced turbulence models [25] and second-order temporal schemes for unsteady flows. [26] Threepoint backward differencing and pseudo-time subiterations are used for time integration, which is referred to as Option-1 in Elmiligui, Abdol-Hamid, and Parlette. [17] Frink [27] describes the inviscid interface reconstruction scheme used with the Roe [28] flux and the viscous discretization. The minmod limiter is applied to the inviscid reconstruction. Forces, moments, and spectra of unsteady pressure for DES cases examined in Elmiligui, AbdolHamid, and Parlette [17] are detailed in this report. The mean values of surface pressures at BL and FS are provided by Elmiligui, Abdol-Hamid, and arlette, [17] but not reproduced in this report. In this study, USM3D results use the DES HRLES model and are explicitly labeled with the flow solver name.

\section{B. FUN3D}

The FUN3D [20] code is a node-centered finite volume scheme (the solution is stored at grid nodes). Anderson and Bonhaus [29] describe the reconstruction scheme for inviscid terms, the viscous discretization, and solution scheme, which results in a nominally second-order spatial discretization. The Roe [28] approximate Riemann solver is used in this study with a unlimited least-squares reconstruction scheme for inviscid terms. The optimized second order backward difference (BDF2OPT) [30] scheme is used for time advancement of the unsteady simulations. Steady results are computed with the Spalart-Allmaras [31] (SA) turbulence model. Both DES [32] (Detached Eddy Simulation) and MDDES [33] (Modified 
DDES [34] (Delayed DES)) are used for the unsteady results. MDDES was developed to alleviate pockets of large eddy viscosity in regions upstream of a cylinder in testing. [33] The MDDES simulations use SA-R [35, 36] and the DES simulations use SA for the RANS portion of HRLES. The advantage of using SA-R with MDDES is that the eddy viscosity is reduced in the regions that have higher vorticity than strain rate, such as in the vortex core where the pure rotation should suppress the turbulence. [35] The SA model is used with DES to match the USM3D implementation to the greatest extent possible. These HRLES capabilities in FUN3D have been compared to wind tunnel and flight measurement for aeroacoustics, [33, 37] unsteady launch vehicle aerodynamics, [38, 39] and F-15 vertical tail buffet. [40]

\section{Temporal Integration}

The FUN3D code uses the BDF2OPT $[30,41]$ time advancement scheme for the HRLES cases. The USM3D code uses the three-point backward differencing and pseudo-time subiteration scheme described by Elmiligui et al. [17] as Option-1. The surface pressures computed with Option-1 showed a small sensitivity to time step. [17] The time accuracy of USM3D and FUN3D was evaluated by Green et al. [42] Both FUN3D [20] and USM3D [26] nondimensionalize time with the freestream speed of sound and the grid unit length. A time step $\Delta t$ is typically chosen by selecting a fraction $(1=N)$ of the nondimensional time required for a particle to travel at freestream Mach number $M$ a characteristic distance $L$,

$$
\Delta t=\frac{L}{M N}
$$

where $L$ is the mean aerodynamic chord. All the unsteady FUN3D results used $\Delta t=1.2248$ $=296.4=(0.242 \times 1000)$. The USM3D results used $\Delta t=5$ and $\Delta t=1$. The FUN3D physical time step is $\Delta \bar{t}=9.4747 \times 10^{-5}$ seconds assuming a freestream speed of sound of $12 ; 927$ in. per second (1,077.2 ft. per second) at standard-day 10,000 ft. pressure altitude. The two USM3D physical time steps are $\Delta \bar{t}=7.7358 \times 10^{-5}$ and $\Delta \bar{t}=3.8679 \times 10^{-4}$ seconds. The FUN3D averaging windows are 8,000 time steps, which is approximately 0.76 seconds or eight free stream passages of the mean aerodynamic chord. USM3D used 16,000 time steps or 1.24 seconds for the fine time step size and 6,000 time steps or 2.32 seconds for the coarse time step size. These data are extracted after the initial start up transients have decayed.

\section{Grids}

Details of the half domain grids used in this study (including images of the surface grid and volume slices) are provided by Elmiligui et al. [16] and are summarized in Table 3. The sides of the outer domain box are approximately 50 mean aerodynamic chords in length. Elmiligui et al. [17] provides further details of the half domain grids (denoted Grid-1) and shows that mirroring the grids to include both starboard and port halves of the aircraft (denoted Grid-2) had a negligible effect on the averaged HRLES surface pressures. As a result of this observation, only the half domain grids will be used for the zero sideslip cases in this article. The FUN3D code stores the flow solution at the nodes of the mesh and USM3D stores the the flow solution at the tetrahedra centers. Therefore, nodes indicates the 
resolution of the FUN3D solutions and tetrahedra indicates the resolution USM3D solutions. The USM3D results labeled with $19 \mathrm{M}$ and $62 \mathrm{M}$ indicate the number of tetrahedra in the coarse grid. The FUN3D results are labeled with $11 \mathrm{M}$ and $24 \mathrm{M}$ to indicate the number of nodes in the medium and fine grids. The given first cell heights result in an average $\mathrm{y}^{+}=1.1$ for the coarse grid and less on the finer meshes. $[16,17]$ The grids were constructed with guidelines from the AIAA Drag Prediction and High Lift Prediction Workshops [16] and no additional refinement was added to resolve off-body vorticies or turbulent structures. The grid is in full-scale inches, which corresponds to the units of BL, FS, and WL.

\section{Results}

Isosurfaces colored with pressure coefficient are provided to show a global view of the upper wind flow features and qualitative differences between a RANS and the two HRLES methods. Medium and fine grids are shown to indicate how grid refinement helps to resolve the features. Next, mean pressure coefficient is shown at constant BL and FS. This is a typical comparison that is made to flight test measurements in CAWAPI reports.

Unsteady results begin with surface plots of standard deviation of fluctuating surface pressure coefficient. This provides a global view of the relative magnitude of unsteadiness on the upper fuselage, lower fuselage, engine inlet, and exhaust plume. More details are provided at FS and BL by showing one standard deviation of pressure coefficient around the mean.

Points are sampled in the volume to compute standard deviation. Frequency spectra are examined at points that exhibit large standard deviation magnitude and changes in magnitude between medium and fine grids. Statistics and frequency spectra of integrated forces and moment complete the examination of the unsteady solution.

\section{A. Isosurfaces}

Isosurfaces of Q criterion [43] are provided for FUN3D to gain a global intuition for the location of vortices predicted by each turbulence model. Q criterion is defined as,

$$
Q=\frac{1}{2}\left(\|\mathbf{\Omega}\|^{2}-\|\mathbf{S}\|^{2}\right)
$$

where $\Omega$ is the rotation rate tensor, $\mathbf{S}$ is the strain rate tensor, and $\|\cdot\|$ is the Frobenius norm. Positive $Q$ defines regions where the vorticity magnitude is greater than the strain-rate magnitude. Snapshots, at the end of the simulation, are shown for the $Q=0.001$ isosurface colored with pressure coefficient in Fig. 3 to Fig. 7. The wing upper surface is shown for four models. Only one half of the domain is simulated with the surfaces mirrored in the $x-Z$ plane to provide two views of the vortical structures and depict the entire symmetric domain. The steady-state solution with SA is shown for two grid resolutions in Fig. 3. Distinct sets of vortices are observed at the wing apex, air dam, outer wing, and surrounding the dummy missile. The isosurfaces of the SA solution appear to be insensitive to grid resolution for these two grid resolutions. The extent of the vorticies is the smallest for all models. The vorticity-based source term of SA predicts an excessive level of eddy viscosity, which dissipates the vorticies. 
Snapshots of the DES simulations are shown in Fig. 4. Vortices are maintained for a longer distance down stream as compared to SA. The main wing leading-edge vortices spiral and break into filaments. Secondary vortices are seen below the main vortex, near the wing leading-edge. The significant difference between DES on the medium and fine grids indicates a strong dependence on grid resolution for these $11 \mathrm{M}$ and $24 \mathrm{M}$ node grids. The secondary vortices are breaking into filaments and becoming entrained in the main vortex for both grids. The secondary vortex entrainment mechanism is more common on the $24 \mathrm{M}$ node grid. Vortex breakup is evident in the outer wing and the distinct vortices seen on the medium grid commingle.

Snapshots of the MDDES simulations are shown in Fig. 5. The medium grid simulation exhibits the breakup of the secondary vortices seen in the fine DES simulation. The topology of the medium and fine grid flow structures is similar with the fine grid exhibiting finer details. The main vortex begins to spiral very near the wing apex. The secondary wing leading-edge vortices are clearly entrained into the main vortex. The secondary vortex entrainment mechanism is more common on the $24 \mathrm{M}$ node grid where these filaments persist inboard the main vortex. Secondary wing leading-edge vortex filaments are transported down the wing leading-edge and disrupt the coherence of the outer wing vortex. Vortices that surround the dummy wing tip missile rail, body, and fins mix with the outer wing vortex filaments.

Views of the top and starboard side are shown for the half of the aircraft simulated with the HRLES methods DES (Fig. 6) and MDDES (Fig. 7). The coherent secondary wing leadingedge vortex of the medium grid is seen in Fig. 6(b), which breaks up on the fine grid, Fig. 6(c and d). The entrainment of the secondary vortex around the main vortex is seen in Fig. 7(c) and the commingling of the vortex filaments is seen in Fig. 7(d). The pressure footprint of the vortex filaments can also be seen in Fig. 7(d) snapshot with pressures alternating above and below freestream pressure on the outer wing section.

\section{B. Mean Section Cut Pressures}

The mean surface pressure coefficient is shown for constant BL slices in Fig. 8 and constant FS slices in Fig. 9. The negative pressure coefficient is depicted; a positive value is suction. The $x$ position is nondimensionalized with local chord and the y position with local wing span, which excludes the dummy missile and rail. The dummy missile and rail are excluded from this presentation because their location is $y /(b / 2)>1$. The peak values of BL 55 and FS 185 negative pressure coefficient are clipped to use the same $\mathrm{C}_{\mathrm{P}}$ scale as companion CAWAPI papers. The BL 55 SA 24M has a peak of $-C_{P}=3.75$ at $x / c=0.045$, the FS 185 DES 24M has a peak of $-C_{P}=4.30$ at $y /(b / 2)=0.79$, and the FS 185 SA $24 \mathrm{M}$ has a peak of $-C_{P}=4.45$ at $y /(b / 2)=0.84$. The heights of these clipped peaks are higher than the values reported by other CAWAPI participants and the flight test measurements.

Overall, SA on both grids overpredicts the suction peaks and displaces these peaks forward or outboard (nearer to the wing leading-edge). Elmiligui, Abdol-Hamid, and Parlette [17] show in their Fig. 9 that the peak of USM3D SA results are also more forward and outboard of the DES mean pressure and flight measurements, but these peaks are lower for the $62 \mathrm{M}$ tetrahedra medium grid than the FUN3D SA results. The HRLES methods are closer to the 
flight test measurements (circles) than SA for a majority of the measurements. The most variation between methods is seen in the wing apex region, the forward portion of BL 55 and BL 70. The DES and MDDES peak negative pressure coefficient level increases and location moves forward with grid refinement for BL 55, BL 70, and BL 80.

The air dam is seen in FS 375 and greater as a vertical line in the simulations. This air dam, described as a wing fence by Grafton, [44] was added to improve lateral and pitch stability at high angles of attack, but is detrimental to vortex lift. This report shows that more suction is maintained on the outer wing upper surface outboard of the air dam, which has a favorable impact on pitch-up and lateral stability. Two mean suction peaks are seen in FS 407.5 and FS 450 outboard of the air dam, which are due to the air dam vortex and outer wing leadingedge vortex. SA has very different $-C_{P}$ levels in the outer section of the wing, BL 184.5, where MDDES $11 \mathrm{M}$ has a slightly higher mean than the other HRLES methods.

\section{Surface Pressure Fluctuations}

Unfortunately, there were no unsteady flow measurements made during the flight tests, but unsteady pressures are examined here to illustrate the differences in the HRLES methods and the effect of increasing grid resolution. These results also provide a database for codeto-code comparison with other CAWAPI participants. To gain a global picture of the unsteady pressure loads on the vehicle, the standard deviation of pressure coefficient is studied for the HRLES methods. This standard deviation is also referred to as the root mean square (RMS) of the pressure coefficient variation from the mean.

The RMS pressure coefficient on the upper surface and symmetry plane is shown for DES in Fig. 10 with a logarithmic color scale. The footprint of the unsteady vorticies are seen at the apex, air dam, and outer wing section. A high level of unsteadiness is also seen in the engine exhaust plume diamond shock pattern. The RMS levels are higher for the fine grid. The RMS pressure coefficient on the lower surface and symmetry plane is shown for DES in Fig. 11. The engine inlet, wing leading-edge, wing trailing-edge, and engine exhaust plume have the highest levels of unsteadiness. The medium grid has an unexplained patch of unsteadiness in front of the wing, below the leading-edge of the canopy. There is no vortex indicated in Fig. 6(a) near this patch, which is not seen on the fine grid.

The RMS pressure coefficient on the upper surface and symmetry plane is shown for MDDES in Fig. 12. The structures are the same as DES, but the levels are higher. The medium grid (Fig. 12(a)) has a lower level of RMS pressure at the wing apex than the fine grid (Fig. 12(b)), but the medium grid has a higher level of unsteadiness on the outer wing section. This MDDES case on the medium $11 \mathrm{M}$ node grid also has slightly different mean values at outer wing section as seen in Fig. 8(f and g) and Fig. 9(e, f, and g). The medium grid MDDES has the same unexplained patch of unsteadiness in front of the wing as seen on the medium grid DES.

One standard deviation of unsteady pressures is shown above and below the mean for constant BL and FS stations in Fig. 14 and Fig. 15. The BL 55 DES 24M mean plus RMS peak of $-C_{P}=3.76$ at $x / c=0.05$ was clipped to have a consistent range with companion CAWAPI report plots. The variation of lower wing surface pressures is much lower than the 
upper surface pressures. The lowest level of variation on the upper surface is inboard, particularly over the fuselage. The variation range of methods on both grid is similar for the inner wing, but the MDDES $11 \mathrm{M}$ medium grid has a slightly higher range on the outer wing, see Fig. 14(e and f) and Fig. 15(d and e). Most of the the flight test measurements are within the unsteady variation of the HRLES methods on both grids. The flight measurements are assumed to be time-averaged mean data, but the unsteady flight pressure may be filtered by the long lengths of 0.028 in. inner diameter tubing used for instrumentation. [2]

\section{Volume Point Pressure Fluctuations}

Pressure coefficient is sampled at a number of points in the domain to examine the off-body flow unsteadiness. These points are arranged in groups of three that extend in the WL direction at constant BL and FS. The RMS of pressure coefficient is shown for USM3D DES on the coarse 19M tetrahedra grid in Fig. 16 for two time step sizes. The level of unsteadiness appears uniform for this logarithmic color scale of RMS. The FUN3D DES results in Fig. 17 show a higher RMS level than USM3D, particularly on the outer wing section and fine grid apex. The FUN3D MDDES results in Fig. 18 show similar RMS levels as the DES results.

Spectra are computed via the method of Welch [45] as implemented in the Octave-Forge pwelsh function. Segments of $2^{11}=2048$ points are used with $50 \%$ overlap between segments with the mean subtracted and the application of a Hamming window. The spectra for two groups of point samples denoted "Apex" and "Outer Wing Leading-Edge" in Fig. 19 are detailed. Sound pressure level (SPL) is computed with a reference sound pressure of 20 $\mu \mathrm{Pa}$. These groups are selected because they have a high RMS level on the fine grid and there is significant variation in the levels between methods and grid resolutions. Frequencies are reported in full-scale, see Section C for simulation time step information and Section D for grid descriptions. The apex spectra are examined first.

The USM3D apex spectra are shown in Fig. 20. A series of strong tones are depicted. The three largest peak tones on the coarse grid are $116 \mathrm{~Hz}, 233 \mathrm{~Hz}$, and $350 \mathrm{~Hz}$ for $\Delta t=5$ and $130 \mathrm{~Hz}, 260 \mathrm{~Hz}, 389 \mathrm{~Hz}$ for $\Delta t=1$. Tones in the medium grid calculation are wider with a peak noise level similar to the FUN3D broadband noise on the fine grid. The FUN3D DES is primarily broadband noise with a weak tone at $164 \mathrm{~Hz}$ for the medium grid and $130 \mathrm{~Hz}$ for the fine grid, Fig. 21. The MDDES method shows a significant peak at $144 \mathrm{~Hz}$ for the medium grid at $165 \mathrm{~Hz}$ and $371 \mathrm{~Hz}$ for the fine grid, Fig. 22. There does not appear to be a single tone that is predicted consistently by these combinations of methods and grids. Both DES and MDDES on the fine grid show very similar broadband noise spectra.

The USM3D outer wing leading-edge spectra are shown in Fig. 23. The $\Delta t=5$ simulation exhibits one tone at $76 \mathrm{~Hz}$ and a steep roll-off at $200 \mathrm{~Hz}$. The FUN3D DES (Fig. 24) and FUN3D MDDES (Fig. 25) signals are broadband for the outer wing leading-edge spectra. The MDDES method on the $11 \mathrm{M}$ grid has the most energy between 100 and $1,000 \mathrm{~Hz}$ of all the methods. Both USM3D DES time steps and FUN3D DES 11M spectra drop below 80 $\mathrm{dB}$ at $1,000 \mathrm{~Hz}$, but the other FUN3D results have energy above $80 \mathrm{~dB}$ at 1,000 Hz. Probe \#43 at FS 452.8, BL 181.1, and WL 94.5 (the most outboard and closest to the upper wing surface) has a higher noise level than other probe locations at this FS. There is more 
similarity between FUN3D and USM3D spectra at these outer wing leading-edge probe locations than at the wing apex.

Without unsteady flight measurements, the flight pressure environment can not be used to determine whether broadband spectra or tonal spectra predictions are appropriate for these locations. A lack of consistent tone frequency predictions may indicate that the tones are an artifact of the simulation or that the flow features have not been sufficiently resolved in space or time.

\section{E. Forces and Moment}

Mean, RMS, minimum, and maximum integrated coefficient of lift $C_{L}$, drag $C_{D}$, and pitching moment $C_{M}$ are examined for the entire sampling window in Table 4, Table 5, and Table 6. For reference, an F-16XL wind tunnel test with flow thorough inlet, wing fence (air dam), nose boom, and missiles at Reynolds number $2.1 \times 10^{6}$ based on mean aerodynamic chord, 20 angle of attack, and 0 angle of sideslip is provided. This test point is from run 200 by Hahne [46] and differs from the simulation in Reynolds number and propulsion modeling. Lift is slightly higher and drag is significantly lower than the mean simulation forces. The mean forces are similar between the SA and HRLES FUN3D results. The USM3D DES has slightly lower lift and higher drag than the FUN3D results. The large time step USM3D has the lowest RMS levels. The FUN3D MDDES 11M has the highest RMS levels. The remaining HRLES methods are within $15 \%$ for RMS $C_{L}$ and $C_{D}$.

The same method is used to compute the spectra of integrated forces and moments as the volume pressures. Spectra are computed via the method of Welch [45] as implemented in the Octave-Forge pwelsh function. Segments of $2^{11}=2048$ points are used with $50 \%$ overlap between segments with the mean subtracted and the application of a Hamming window. The USM3D coarse grid simulations have the lowest broadband noise levels with peaks at $76 \mathrm{~Hz}$, $116 \mathrm{~Hz}$, and $232 \mathrm{~Hz}$ for $\Delta t=5$ and $130 \mathrm{~Hz} \Delta t=1$. The medium grid USM3D $\Delta t=5$ simulation shows an increase in broadband noise over the coarse grid simulations. The peaks of force and moment spectra at $116 \mathrm{~Hz}$ and $232 \mathrm{~Hz}$ at the same frequencies the $116 \mathrm{~Hz}$ and $233 \mathrm{~Hz}$ observed in the $\Delta t=5$ volume apex point spectra. The unsteady forces are broadband for FUN3D with the levels increasing with grid refinement and from DES to MDDES.

\section{Conclusions}

The HRLES model in FUN3D and USM3D are applied to the F-16XL-1 in the framework of the CAWAPI project. Q criteria isosurfaces provide a global view of the vortex structures, their coherency, and how these vortices interact. Mean surface pressure coefficient at constant BL and FS indicated that steady RANS SA overpredicted the maximum value of suction peak and predicted it too near the wing leading-edge. Mean HRLES pressures provide a better comparison to flight test measurements. The mean pressure coefficient has the most spread between methods in the wing apex region. The outer wing has clear indication of the average suction peaks of both air dam and wing leading-edge vortices. The medium 11M node MDDES solution has a different mean value than the other HRLES 
models for outer wing upper surface. Both SA resolutions have a stronger wing leading-edge vortex suction and weaker air dam vortex suction than the HRLES mean pressure.

The RMS values of unsteady surface pressure coefficients provide a global view of the unsteadiness and the relative magnitude of the variation over the entire aircraft. The medium grid HRLES simulations have a quieter wing apex and higher levels of unsteadiness in the outer wing section than fine grid HRLES. The medium grid HRLES simulations have a patch of unsteadiness on the side of the forward fuselage not seen on the fine grid or the $\mathrm{Q}$ criteria isosurface.

The USM3D simulation had lower levels of RMS pressure at sampled volume points. The fine grid FUN3D HRLES has higher RMS values for the apex than medium grid HRLES or USM3D. Many of the volume points over the outer portion of the wing exhibited high RMS values, particularly at the wing leading-edge and near the air dam. These high levels are most likely due to vorticies in those regions that can be seen to be spiraling and commingling in the Q criteria isosurfaces. The USM3D simulation apex volume points have many pure tones with low broadband noise. The width of these tones increased with grid refinement. The peak noise of these tones are similar to fine grid FUN3D broadband noise. The FUN3D simulations show weak tones and a dramatic increase in apex broadband noise with grid refinement. The outer wing leading-edge spectra has a similar broadband shape for all methods. These outer wing points are less sensitive to time step and grid refinement. There is also less variation between FUN3D and USM3D outer wing pressure spectra than wing apex spectra. The medium 11M node grid MDDES has the highest level of outer-wing leading-edge broadband noise, which is also seen in RMS surface pressures. The medium $11 \mathrm{M}$ MDDES also has a slightly different mean coefficient pressure than the other three FUN3D HRLES simulations.

The forces and moment spectra are primarily broadband. The exceptions are the tones seen in the large time step USM3D apex volume points are present in the forces and moments for that model. The mean values of lift and drag of the FUN3D models are very similar. The mean USM3D lift, drag, and pitching moment are similar for the two different time step sizes, but lower in lift, higher in drag, and higher in pitching moment than the FUN3D means.

As seen in previous CAWAPI studies, the HRLES methods provided an improved prediction of steady surface pressure flight measurements over RANS (in this case SA). The Q criterion snapshots allowed for an interpretation of how the important flow structures generate, evolve, and interact. The fusion of $\mathrm{Q}$ criterion and standard deviation of pressure fluctuation permitted the interpretation of the effects of these coherent or commingled vortical structures. The interpretation of pressure and force fluctuation spectra is still ongoing and may be aided by examining the simulations in other CAWAPI reports, because unsteady flight or wind tunnel measurements are not available for comparison.

\section{Acknowledgments}

Veer Vatsa, NASA Langley Research Center, and David Lockhard, NASA Langley Research Center, shared their extensive experience on unsteady simulation and data reduction. Bil Kleb, NASA Langley Research Center, 
provided assistance on data reduction and a review of the manuscript. Craig Streett, NASA Langley Research Center, made constructive suggestions, which improved the clarity and presentation of unsteady data. Beth LeeRausch, NASA Langley Research Center, Troy Lake, University of Wyoming, and Steve Bauer, NASA Langley Research Center, provided insightful feedback on this article.

\section{References}

[1]. Obara CJ and Lamar JE, "Overview of the Cranked-Arrow Wing Aerodynamics Project International," AIAA Journal of Aircraft, Vol. 46, No. 2, March-4 2009, pp. 355368.doi:10.2514/1.34957.

[2]. Lamar JE, Obara CJ, Fisher BD, and Fisher DF, "Flight, Wind-Tunnel, and Computational Fluid Dynamics Comparison for Cranked Arrow Wing (F-16XL-1) at Subsonic and Transonic Speeds," NASA TP-2001-21062, Langley Research Center, 2 2001. doi:2060/20010047400.

[3]. Sakata K, "Japan's Supersonic Technology and Business Jet Perspectives," AIAA Paper 2013-21, 2013.

[4]. Herrmann U, "Low-Speed High-Lift Performance Improvements Obtained and Validated by the EC-Project EPISTLE," 24th International Congress of the Aeronautical Sciences (ICAS), ICAS Paper 2004-4.1.1, Sept. 2004.

[5]. Antani DL and Morgenstern JM, "HSCT High-Lift Aerodynamic Technology Requirements," AIAA Paper 92-4228, 1992.

[6]. Benoliel AM, Aerodynamic Pitch-up of Cranked Arrow Wings. Estimation, Trim, and Configuration Design, Master's thesis, Virginia Polytechnic Institute and State University, 5 1994. doi:10919/35656.

[7]. Morgenstern J, Norstrud N, Sokhey J, Martens S, and Alonso JJ, “Advanced Concept Studies for Supersonic Commercial Transports Entering Service in the 2018 to 2020 Period," NASA CR-2013-217820, Langley Research Center, Feb. 2013. doi:2060/20130010174.

[8]. Magee TE, Wilcox PA, Fugal SR, Acheson KE, Adamson EE, Bidwell AL, and Shaw SG, "System-Level Experimental Validations for Supersonic Commercial Transport Aircraft Entering Service in the 2018-2020 Time Period, Phase I Final Report,” NASA CR-2013-217797, Langley Research Center, 2 2013. doi:2060/20130011026.

[9]. Rizzi A, Jirásek A, Lamar JE, Crippa S, Badcock KJ, and Boelens OJ, "Lessons Learned from Numerical Simulations of the F-16XL Aircraft at Flight Conditions," AIAA Journal of Aircraft, Vol. 46, No. 2, March-4 2009, pp. 423-441. doi:10.2514/1.35698.

[10]. Morton SA, McDaniel DR, and Cummings RM, "F-16XL Unsteady Simulations for the CAWAPI Facet of RTO Task Group AVT-113,” AIAA Paper 2007-493, 2007.

[11]. Görtz S and Jirásek A, "Steady and Unsteady CFD Analysis of the F-16XL using the Unstructured Edge Code," AIAA Paper 2007-678, 2007.

[12]. Luckring JM, Rizzi A, and Davis MB, "Toward Improved CFD Predictions of Slender Airframe Aerodynamics Using the F-16XL Aircraft (CAWAPI-2),” AIAA Paper 2014-419, 2014.

[13]. Rizzi A and Luckring JM, "What was Learned in Predicting Slender Airframe Aerodynamics with the F16-XL Aircraft," AIAA Paper 2014-759, 2014.

[14]. Slotnick J, Khodadoust A, Alonso J, Darmofal D, Gropp W, Lurie E, and Mavriplis D, "CFD Vision 2030 Study. A Path to Revolutionary Computational Aerosciences," NASA CR-2014218178, Langley Research Center, 3 2014. doi:2060/20140003093.

[15]. Lamar JE and Abdol-Hamid KS, "USM3D Unstructured Grid Solutions for CAWAPI at NASA LaRC," AIAA Paper 2007-682, 2007.

[16]. Elmiligui A, Abdol-Hamid K, Cavallo PA, and Parlette EB, "Numerical Simulations For the F-16XL Aircraft Configuration,” AIAA Paper 2014-756, 2014.

[17]. Elmiligui A, Abdol-Hamid K, and Parlette EB, "Detached Eddy Simulation for the F-16XL Aircraft Configuration," AIAA Paper 2015-1496, 2015.

[18]. U.S. Standard Atmosphere, 1976, U.S. Government Printing Office, 1976.

[19]. Carlson J-R, "Inflow/Outflow Boundary Conditions with Application to FUN3D," NASA TM-2011-217181, Langley Research Center, 10 2011. doi:2060/20110022658. 
[20]. Biedron RT, Carlson J-R, Derlaga JM, Gnoffo PA, Hammond DP, Jones WT, Kleb B, Lee-Rausch EM, Nielsen EJ, Park MA, Rumsey CL, Thomas JL, and Wood WA, "FUN3D Manual. 12.7," NASA TM-2015-218761, Langley Research Center, 5 2015. doi:2060/20150008956.

[21]. Hartwich PM and Frink NT, "Estimation of Propulsion-Induced Effects on Transonic Flows Over a Hypersonic Configuration," AIAA Paper 1992-523, 1992.

[22]. Boelens OJ, Badcock KJ, Gortz S, Morton S, Fritz W, Karman SL Jr., Michal T, and Lamar JE, "F-16XL Geometry and Computational Grids Used in Cranked-Arrow Wing Aerodynamics Project International," AIAA Journal of Aircraft, Vol. 46, No. 2, March-4 2009, pp. 369-376. doi:10.2514/1.34852.

[23]. Frink NT, “Tetrahedral Unstructured Navier-Stokes Method for Turbulent Flow,” AIAA Journal, Vol. 36, No. 11, 11 1998, pp. 1975-1982.

[24]. Frink NT, Pirzadeh SZ, Parikh P, Pandya MJ, and Bhat MK, "The NASA Tetrahedral Unstructured Software System,” The Aeronautical Journal, Vol. 104, No. 1040, 10 2000, pp. 491-499.

[25]. Pandya MJ, Abdol-Hamid KS, and Frink NT, "Enhancement of USM3D Unstructured Flow Solver for High-Speed High-Temperature Shear Flows," AIAA Paper 2009-1329, 2010.

[26]. Pandya MJ, Frink NT, Abdol-Hamid KS, and Chung JJ, "Recent Enhancements to USM3D Unstructured Flow Solver for Unsteady Flows,” AIAA Paper 2004-5201, 2004.

[27]. Frink NT, "Recent Progress Toward a Three-Dimensional Unstructured Navier-Stokes Flow Solver," AIAA Paper 94-61, 1994.

[28]. Roe PL, “Approximate Riemann Solvers, Parameter Vectors, and Difference Schemes," Journal of Computational Physics, Vol. 43, No. 2, 10 1981, pp. 357-372. doi:10.1016/0021-9991(81)90128-5.

[29]. Anderson WK and Bonhaus DL, "An Implicit Upwind Algorithm for Computing Turbulent Flows on Unstructured Grids,” Computers and Fluids, Vol. 23, No. 1, 1994, pp. 1-22. doi:10.1016/0045-7930(94)90023-X.

[30]. Vatsa VN, Carpenter MH, and Lockard DP, "Re-evaluation of an Optimized Second Order Backward Difference (BDF2OPT) Scheme for Unsteady Flow Applications," AIAA Paper 2010122, 2010.

[31]. Spalart PR and Allmaras SR, "A One-Equation Turbulence Model for Aerodynamic Flows," La Recherche Aerospatiale, Vol. 1, 1994, pp. 5-21.

[32]. Spalart PR, Jou W-H, Strelets M, and Allmaras SR, "Comments on the Feasibility of LES for Wings, and on a Hybrid RANS/LES Approach," Proceedings of the First ASOSR Conference on DNS/LES, 81997.

[33]. Vatsa VN and Lockard DP, “Assessment of Hybrid RANS/LES Turbulence Models for Aeroacoustics Applications,” AIAA Paper 2010-4001, 2010.

[34]. Spalart PR, Deck S, Shur ML, Squires KD, Strelets MK, and Travin A, "A New Version of Detachededdy Simulation, Resistant to Ambiguous Grid Densities," Theoretical and Computational Fluid Dynamics, Vol. 20, No. 3, July 2006, pp. 181-195. doi:10.1007/ s00162-006-0015-0.

[35]. Dacles-Mariani J, Zilliac GG, Chow JS, and Bradshaw P, "Numerical/Experimental Study of a Wingtip Vortex in the Near Field," AIAA Journal, Vol. 33, No. 9, 9 1995, pp. 1561-1568. doi: $10.2514 / 3.12826$.

[36]. Dacles-Mariani J, Kwak D, and Zilliac G, “On Numerical Errors and Turbulence Modeling in Tip Vortex Flow Prediction,” International Journal for Numerical Methods in Fluids, Vol. 30, No. 1, 1999, pp. 65-82. doi:10.1002/(SICI)1097-0363(19990515)30.1<65..AID-FLD839>3.0.CO;2-Y.

[37]. Vatsa V, Khorrami MR, Park MA, and Lockard DP, “Aeroacoustic Simulation of Nose Landing Gear on Adaptive Unstructured Grids With FUN3D,” AIAA Paper 2013-2071, 2013.

[38]. Brauckmann GJ, Streett CL, Kleb WL, Alter SJ, Murphy KJ, and Glass CE, "Computational and Experimental Unsteady Pressures for Alternate SLS Booster Nose Shapes," AIAA Paper 2015559, 2015.

[39]. Alter SJ, Brauckmann GJ, Kleb B, Glass CE, Streett CL, and Schuster DM, "Time-Accurate Unsteady Pressure Loads Simulated for the Space Launch System at Wind Tunnel Conditions," AIAA Paper 2015-3149, 2015. 
[40]. Yang S, Chen PC, Wang XQ, Mignolet MP, and Pitt DM, "Aerodynamics of the F-15 at High Angle of Attack," AIAA Paper 2015-549, 2015.

[41]. Vatsa VN and Carpenter MH, "Higher-Order Temporal Schemes with Error Controllers for Unsteady Navier-Stokes Equations,” AIAA Paper 2005-5245, 2005.

[42]. Green BE, Czerwiec R, Cureton C, Lillian C, Kernazhitskiy S, Eymann T, Torres J, Bergeron K, and Decker R, "Evaluation of Flow Solver Accuracy using Five Simple Unsteady Validation Cases," AIAA Paper 2011-29, 2011.

[43]. Hunt JCR, Wray AA, and Moin P, "Eddies, Streams, and Convergence Zones in Turbulent Flows," Studying Turbulence Using Numerical Simulation Databases, 2. Proceedings of the 1988 Summer Program, Stanford University, Dec. 1988, pp. 193-208. doi:2060/19890015184.

[44]. Grafton SB, "Low-Speed Wind-Tunnel Study of the High-Angle-of-Attack Stability and Control Characteristics of a Cranked-Arrow-Wing Fighter Configuration," NASA TM-85776, Langley Research Center, 5 1984. doi:2060/19840015586.

[45]. Welch PD, “The Use of Fast Fourier Transform for the Estimation of Power Spectra. A Method Based on Time Averaging Over Short, Modified Periodograms," IEEE Transactions on Audio and Electroacoustics, Vol. 15, No. 2, 6 1967, pp. 70-73. doi:10.1109/TAU.1967.1161901.

[46]. Hahne DE, "Low-Speed Aerodynamic Data for an 0.18-Scale Model of an F-16XL with Various Leading-Edge Modifications," NASA TM-1999-209703, Langley Research Center, 121999. doi:2060/20000021569. 


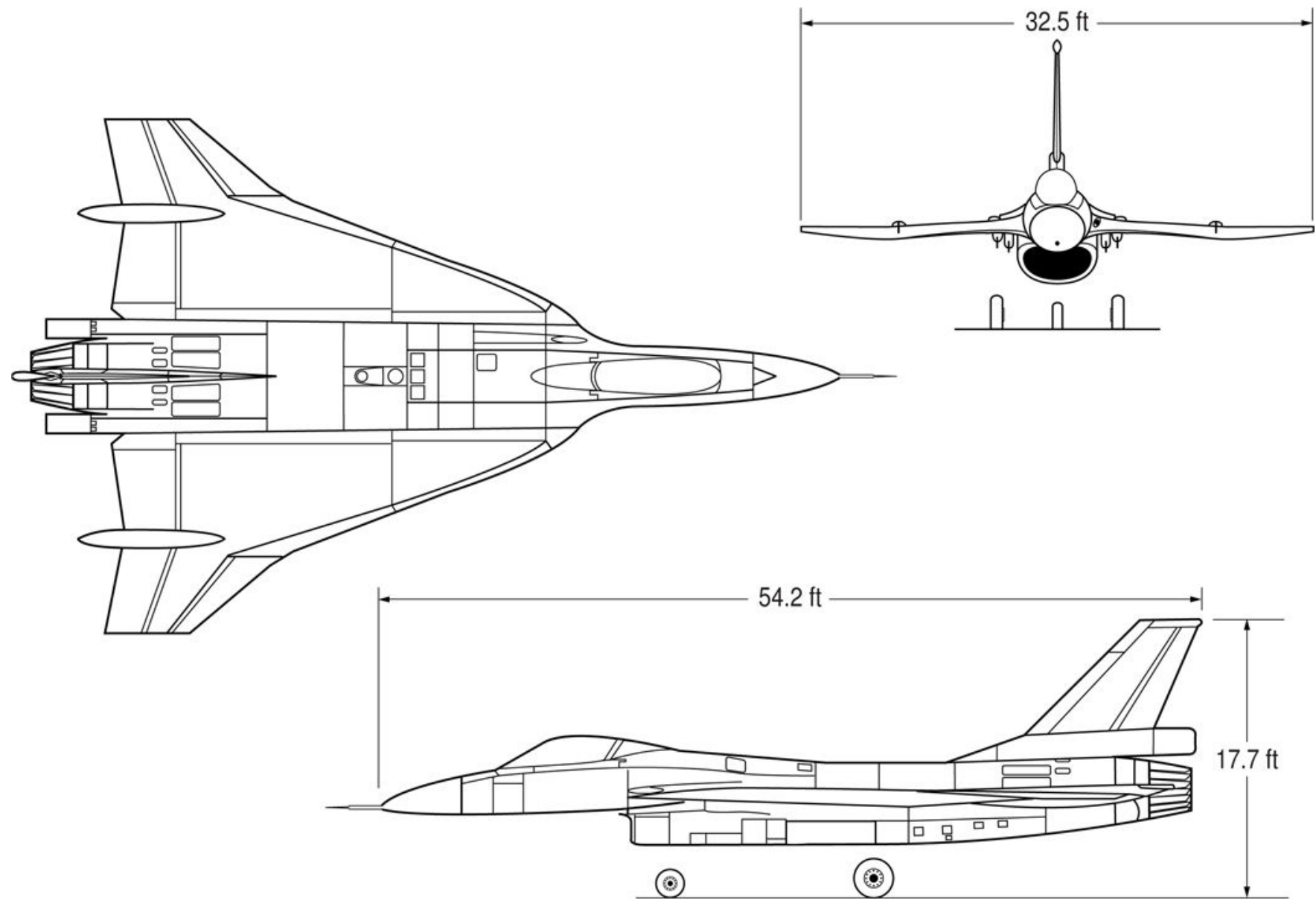

Figure 1.

Three-view drawing of F-16XL-1 airplane. 


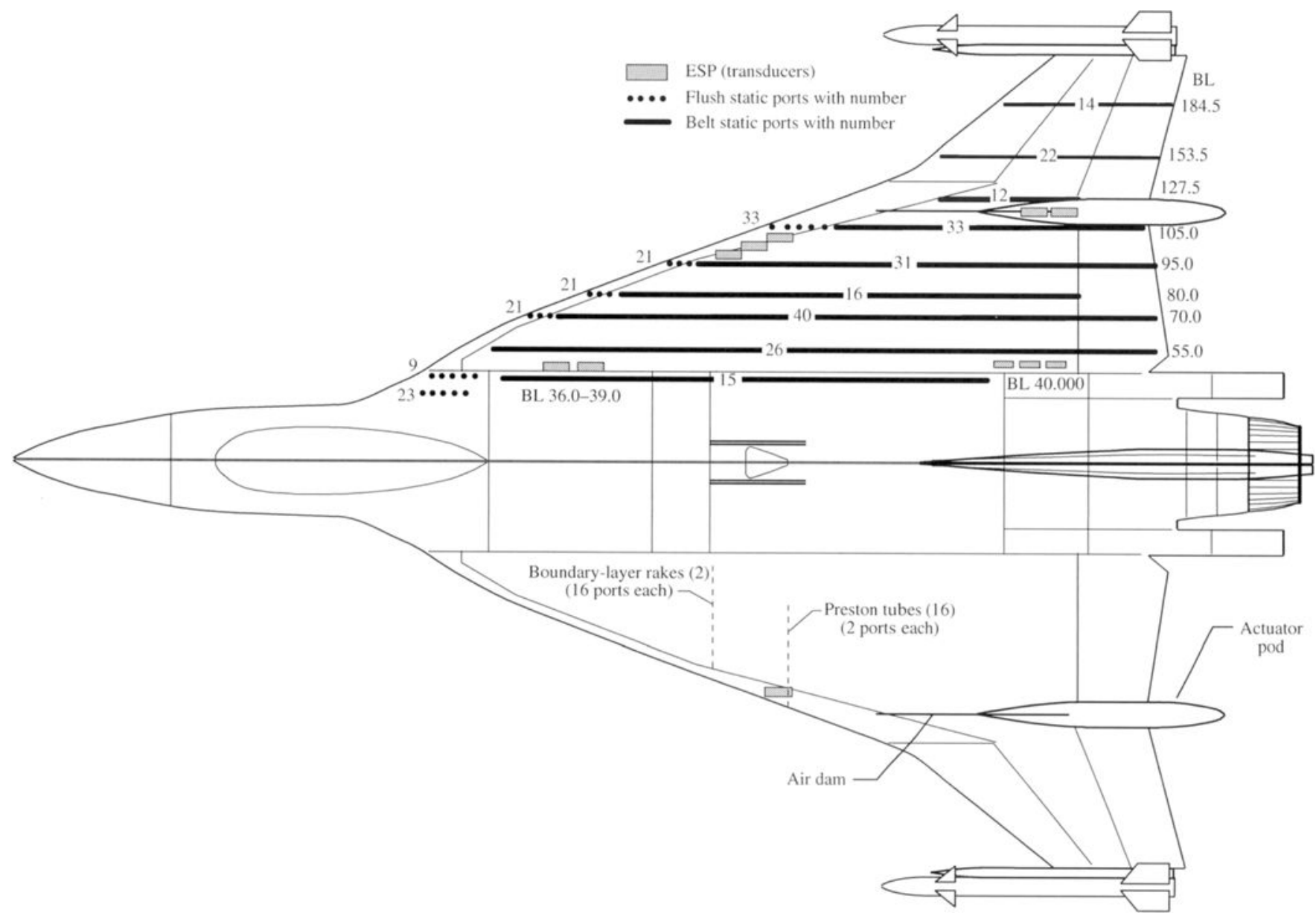

Figure 2.

Planform drawing of F-16XL-1 airplane indicating the location of the pressure instrumentation. [2] 

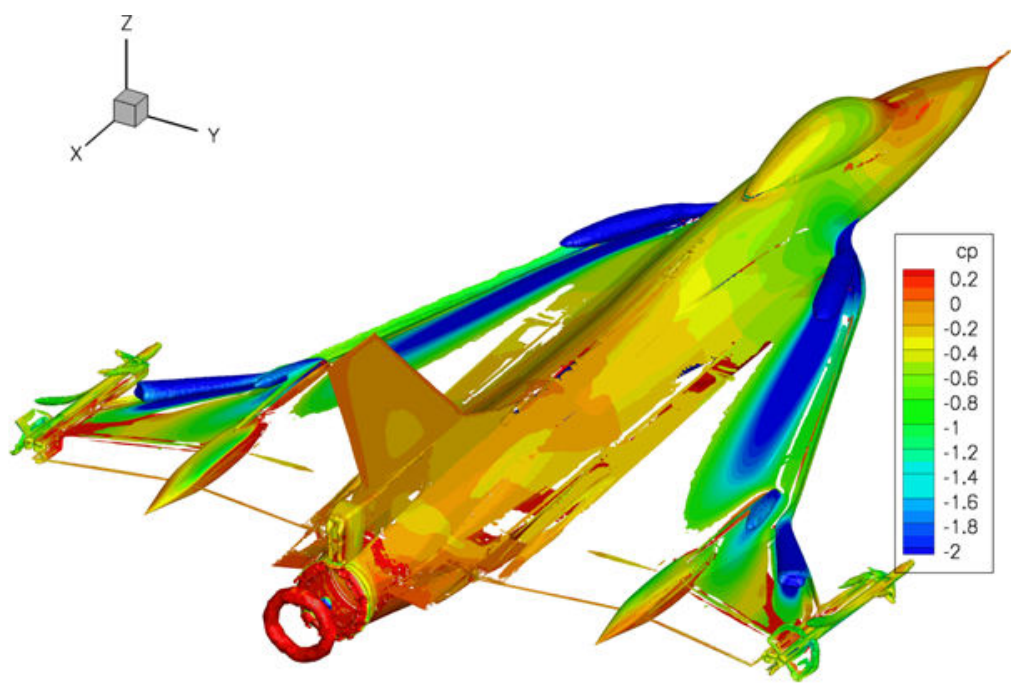

a) Medium grid, 11M.

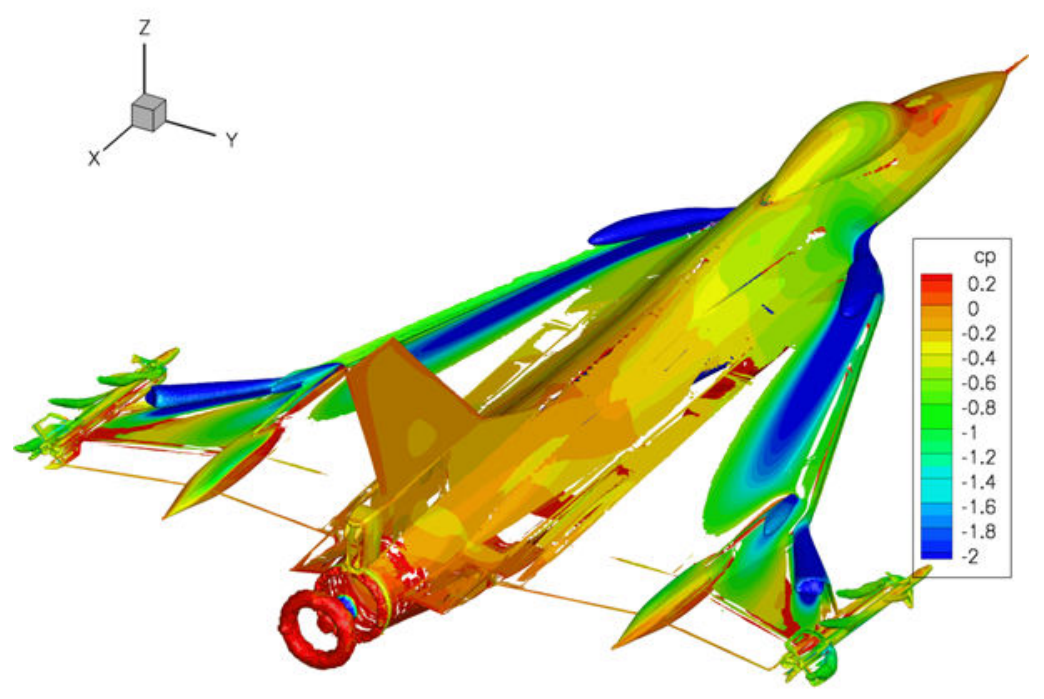

b) Fine grid, 24M.

Figure 3.

Snapshot of Q criterion colored with pressure coefficient for FUN3D SA. 

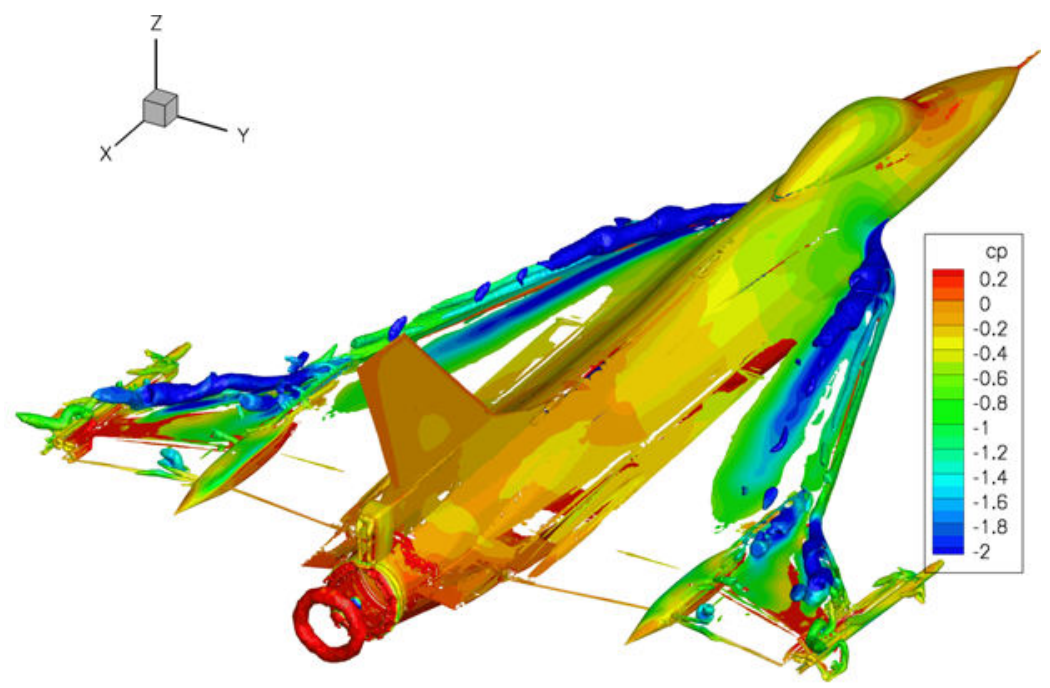

a) Medium grid, $11 \mathrm{M}$.

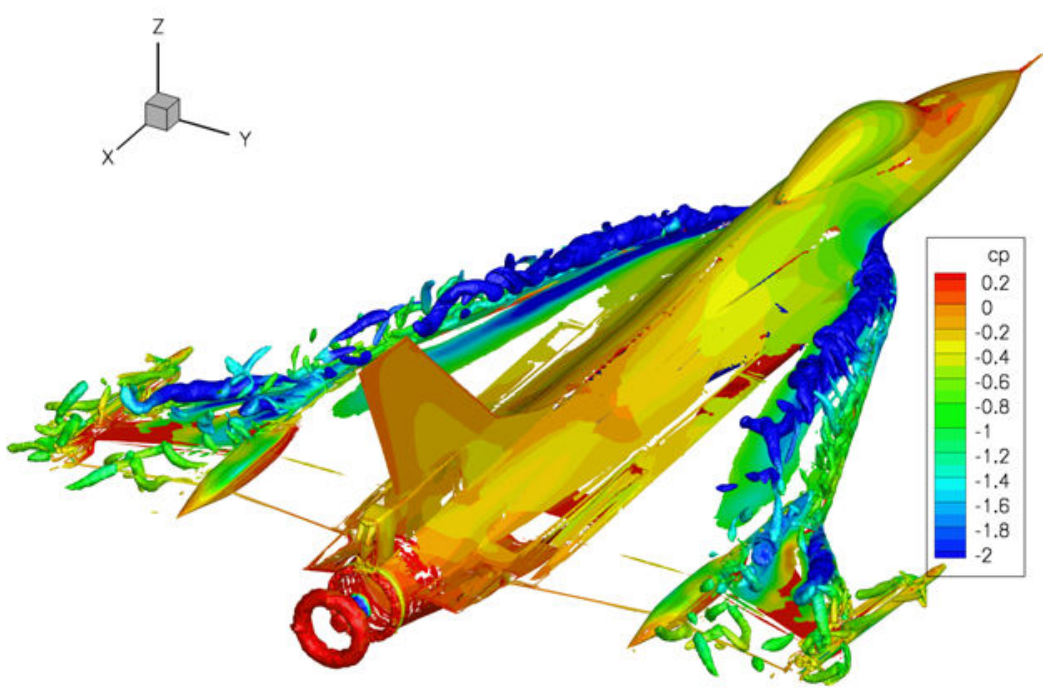

b) Fine grid, 24M.

Figure 4.

Snapshot of Q criterion colored with pressure coefficient for FUN3D DES. 

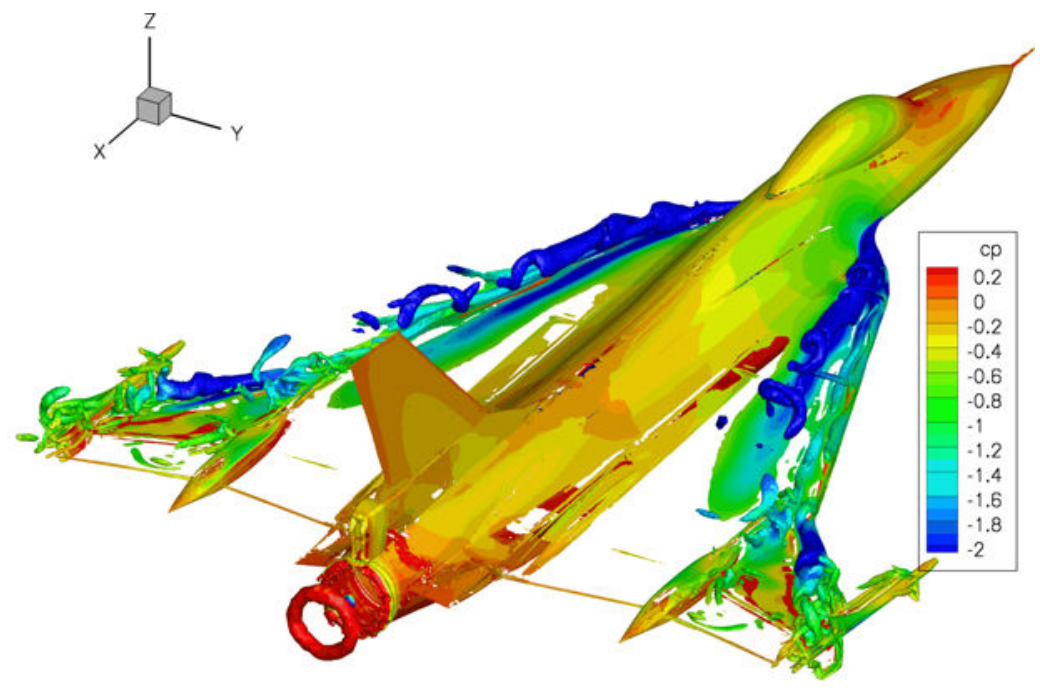

a) Medium grid, 11M.

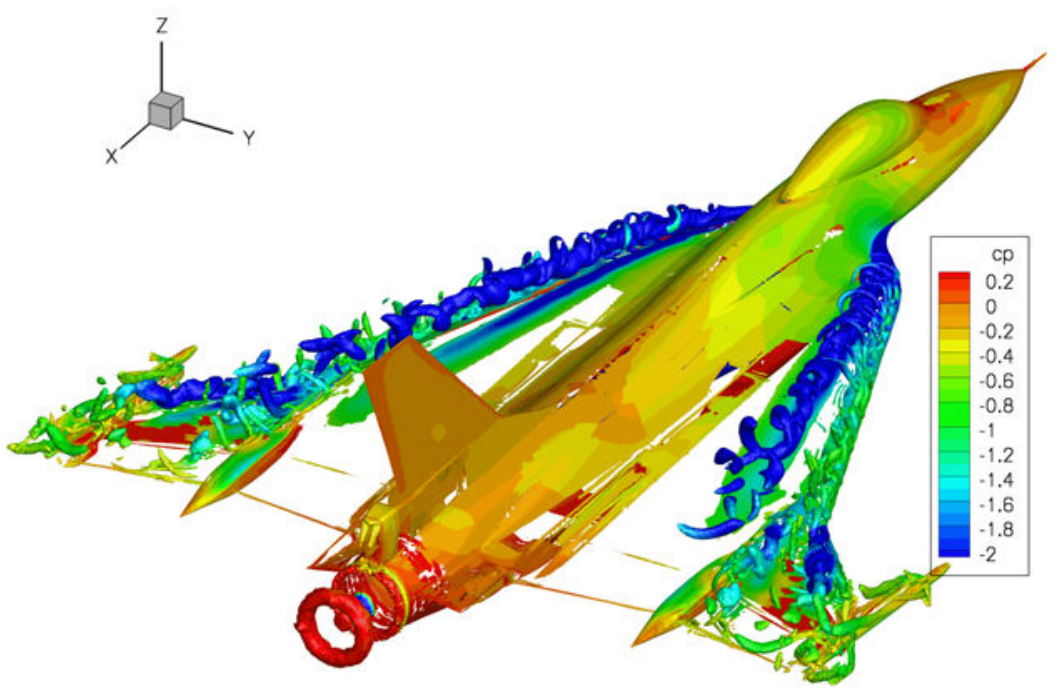

b) Fine grid, 24M.

Figure 5.

Snapshot of Q criterion colored with pressure coefficient for FUN3D MDDES. 


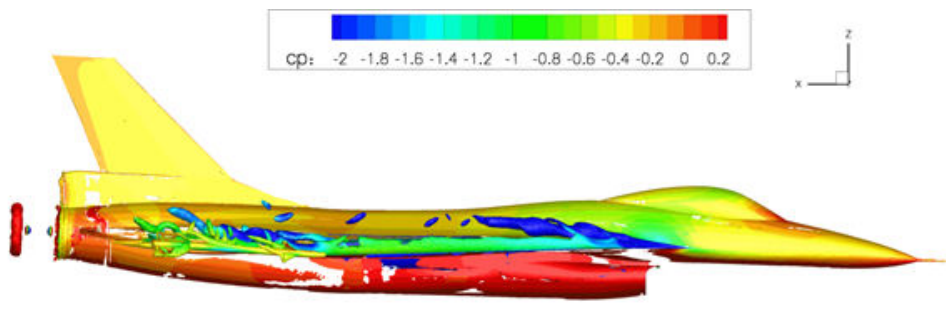

a) Medium grid, $11 \mathrm{M}$, side view.

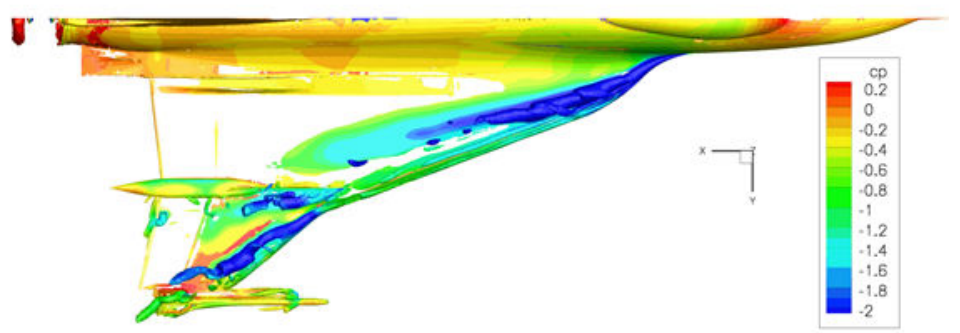

b) Medium grid, 11M, top-down view.

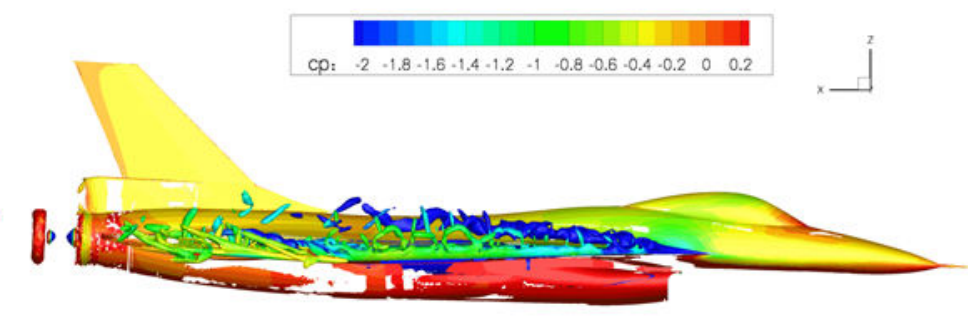

c) Fine grid, 24M, side view.

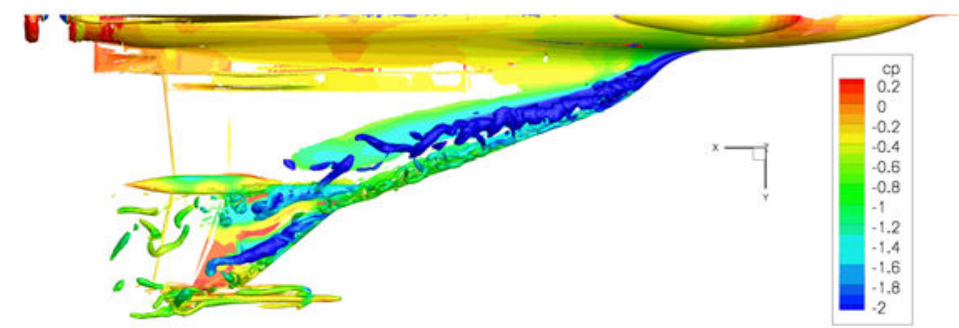

d) Fine grid, 24M, top-down view.

Figure 6.

Snapshot of Q criterion colored with pressure coefficient for FUN3D DES. 


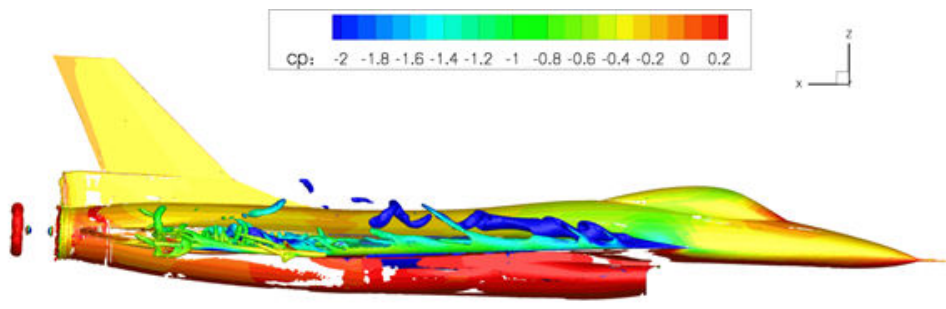

a) Medium grid, $11 \mathrm{M}$, side view.

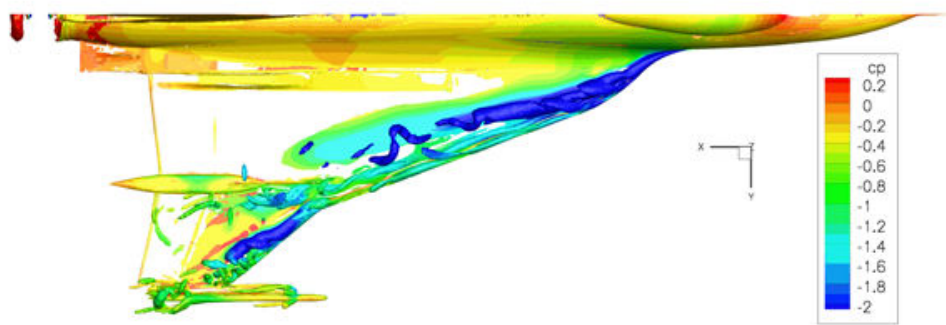

b) Medium grid, 11M, top-down view.

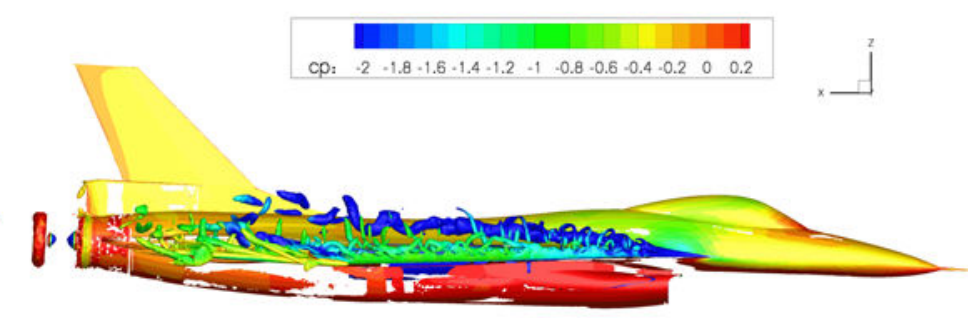

c) Fine grid, 24M, side view.

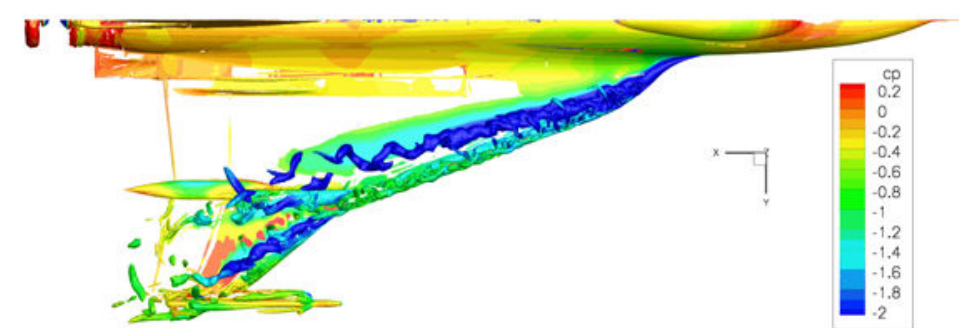

d) Fine grid, 24M, top-down view.

Figure 7.

Snapshot of Q criterion colored with pressure coefficient for FUN3D MDDES. 


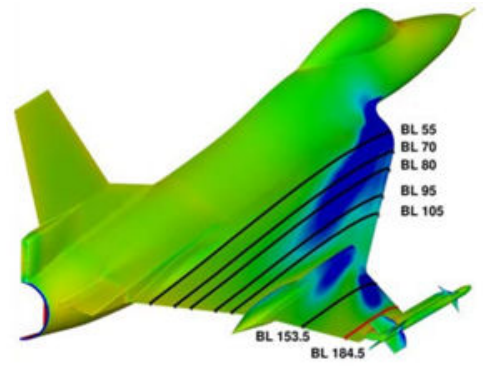

a) BL locations depicted on surface $C_{P}$. [17]

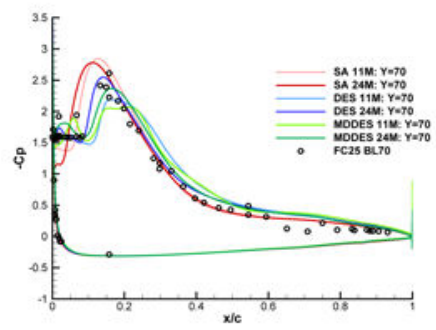

c) BL 70.

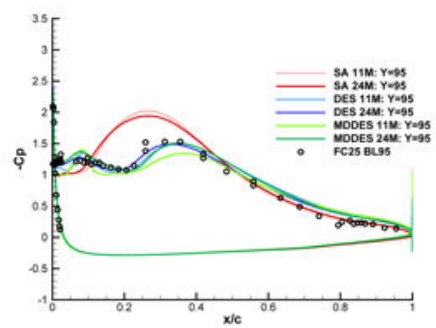

e) BL 95 .

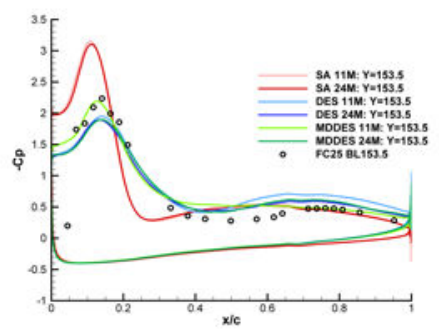

g) BL 153.5.

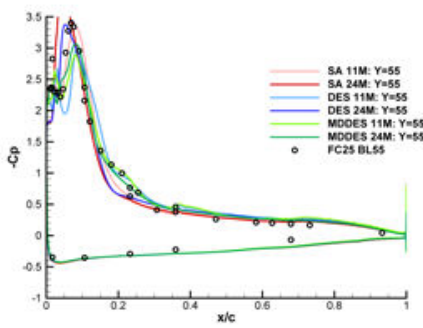

b) BL 55 .

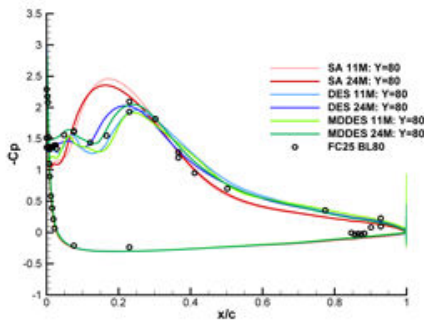

d) BL 80.

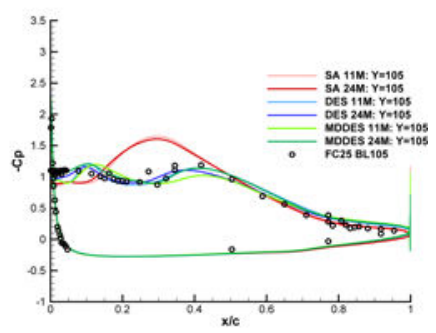

f) BL 105.

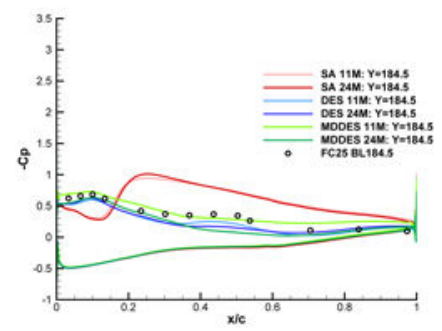

h) BL 184.5.

Figure 8.

FUN3D time-averaged coefficient of surface pressure along butt lines. 


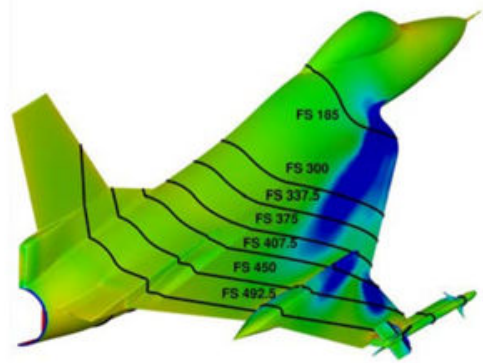

a) FS locations depicted on surface $C_{P}$. [17]

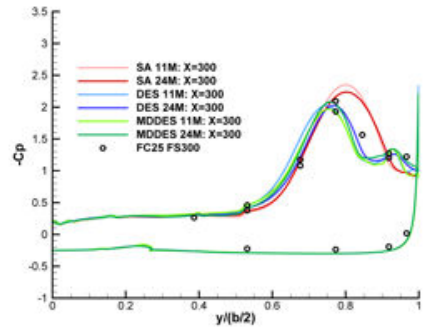

c) FS 300 .

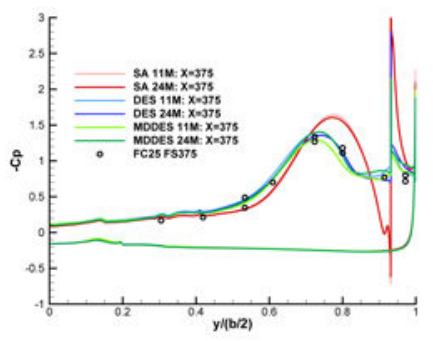

e) FS 375 .

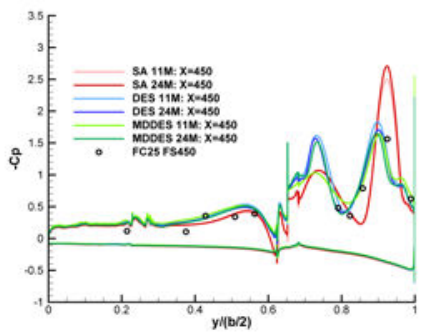

g) $\mathrm{FS} 450$.

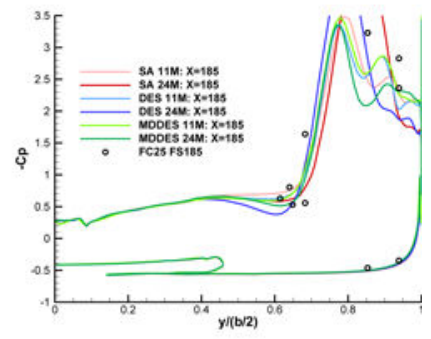

b) FS 185 .

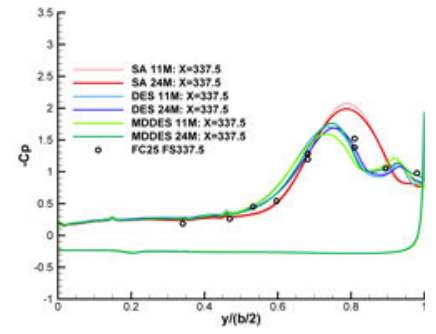

d) FS 337.5.

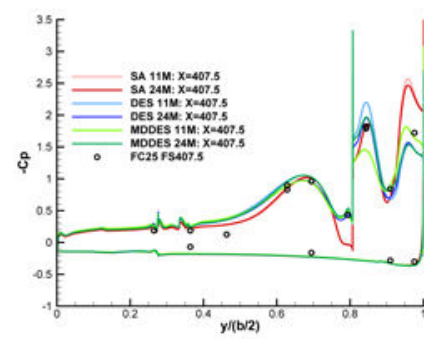

f) $\mathrm{FS} 407.5$.

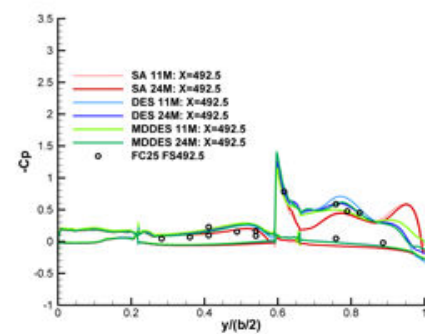

h) FS 492.5.

Figure 9.

FUN3D time-averaged coefficient of surface pressure along fuselage station lines. 


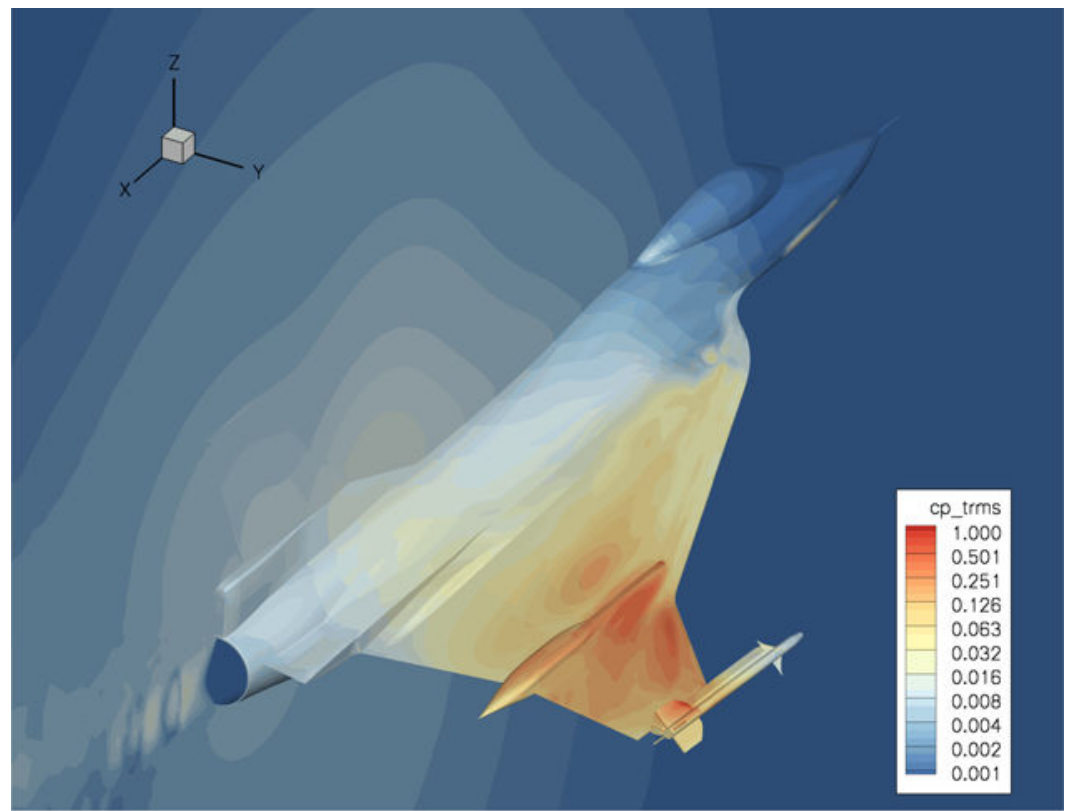

a) Medium grid, $11 \mathrm{M}$.

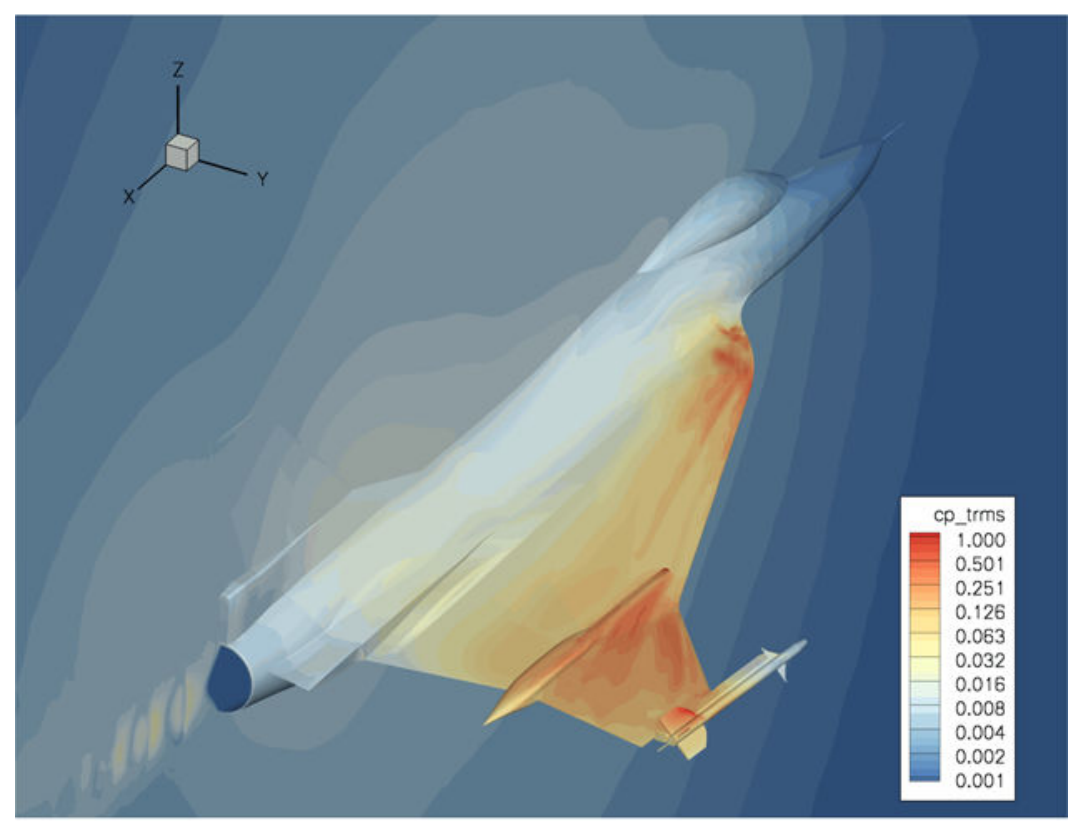

b) Fine grid, 24M.

Figure 10.

Upper surface pressure coefficient RMS variation for FUN3D DES. 


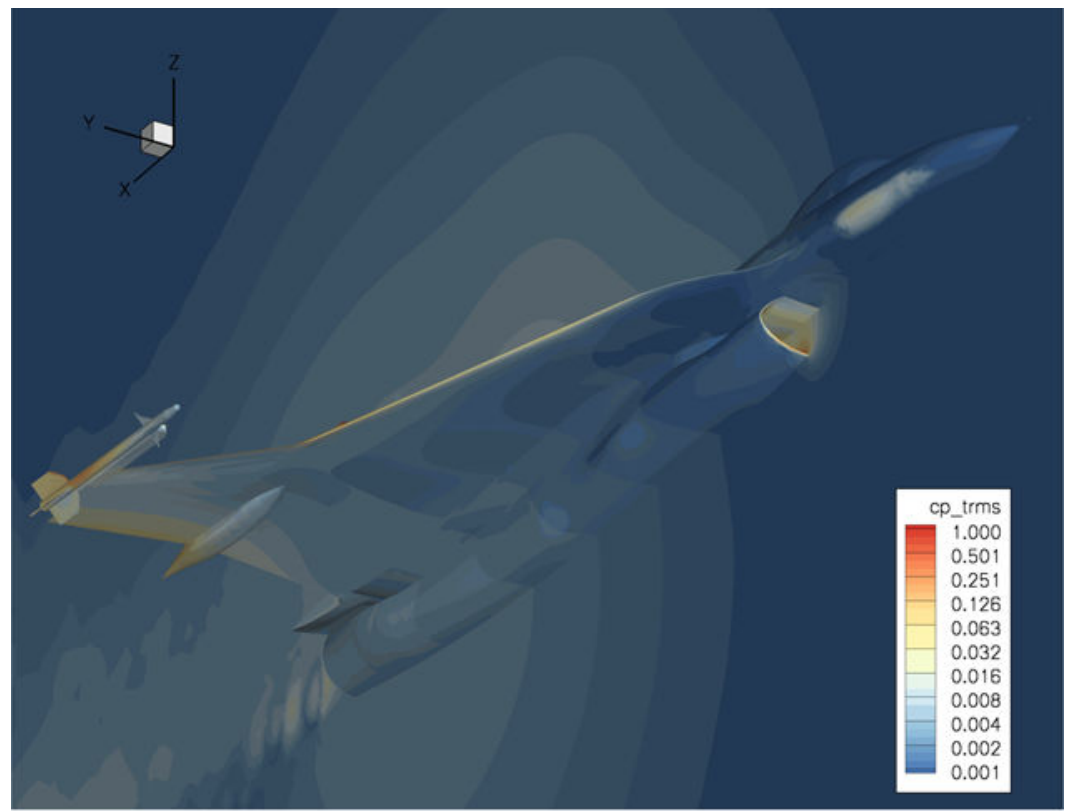

a) Medium grid, $11 \mathrm{M}$.

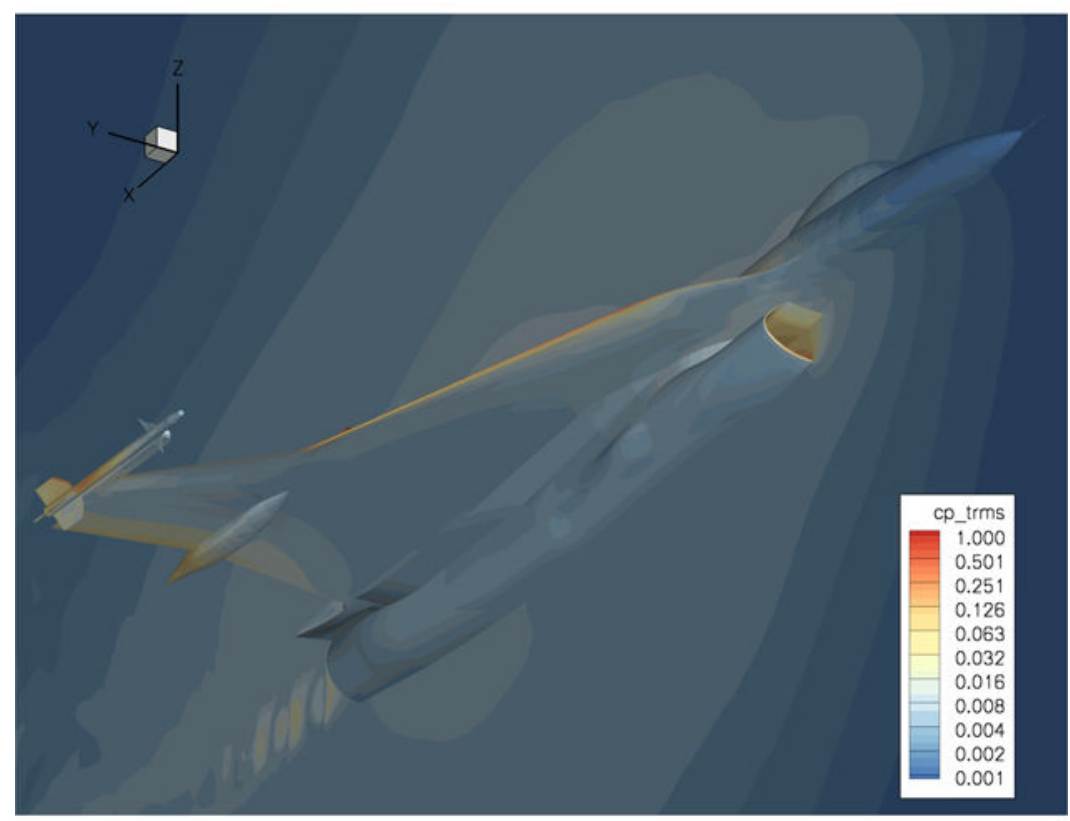

b) Fine grid, 24M.

Figure 11.

Lower surface pressure coefficient RMS variation for FUN3D DES. 


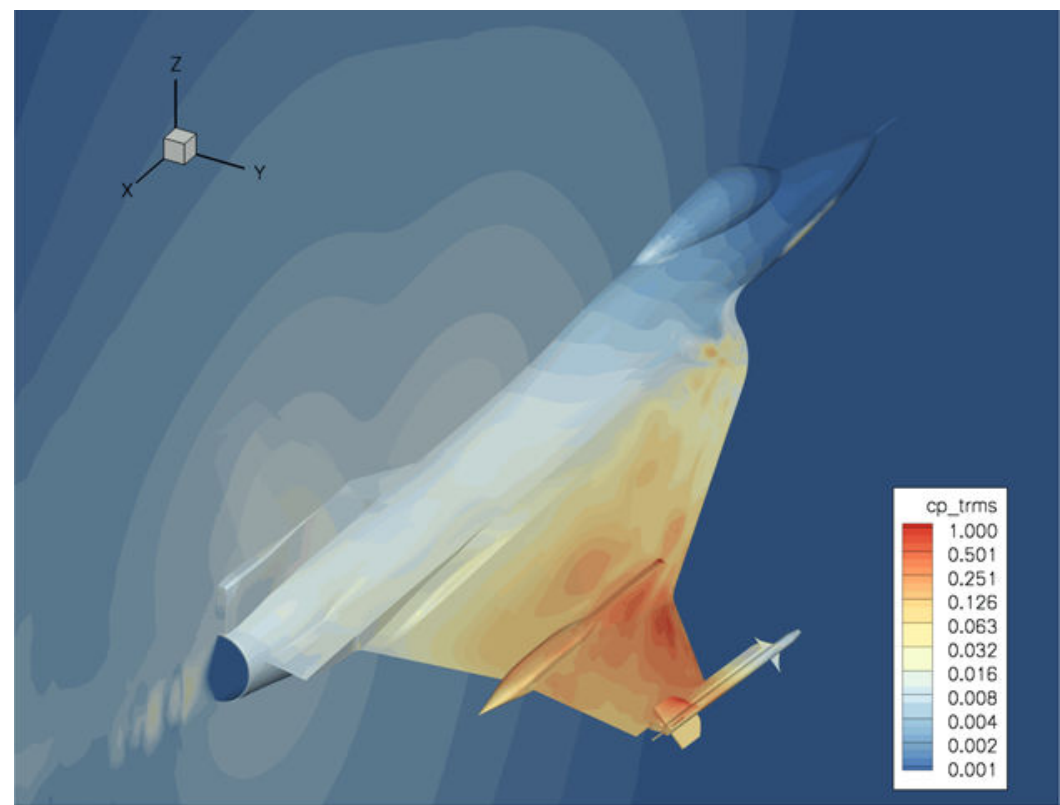

a) Medium grid, $11 \mathrm{M}$.

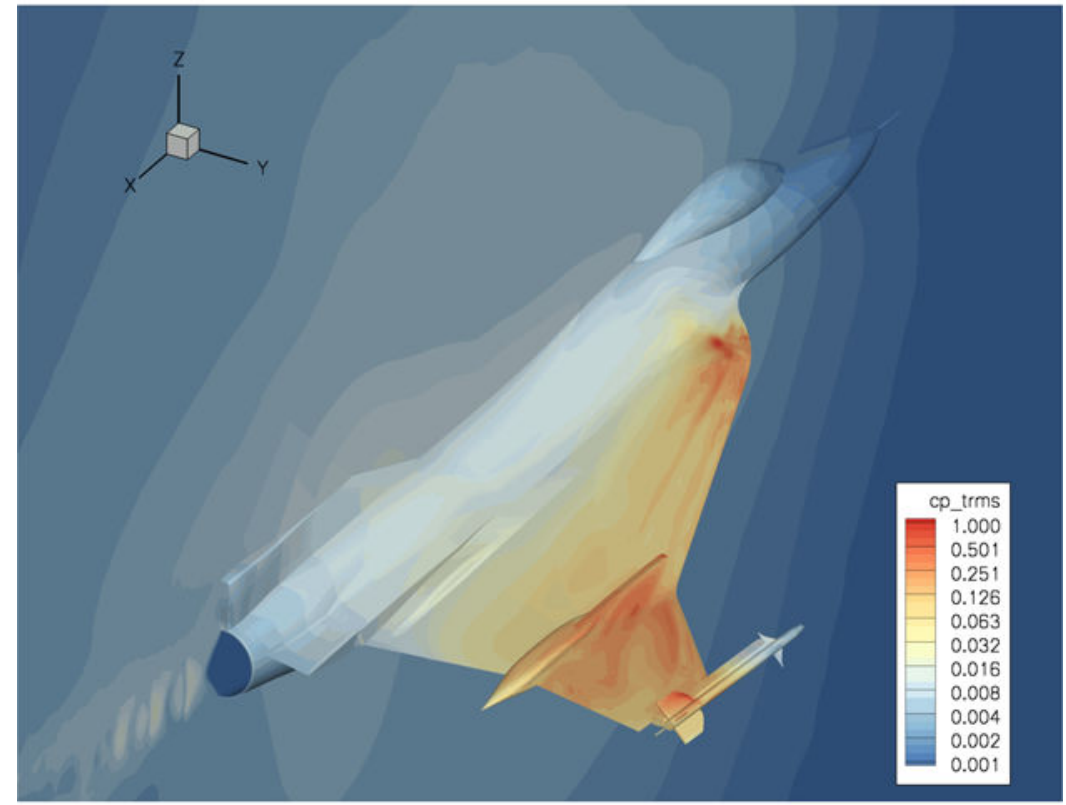

b) Fine grid, 24M.

Figure 12.

Upper surface pressure coefficient RMS variation for FUN3D MDDES. 


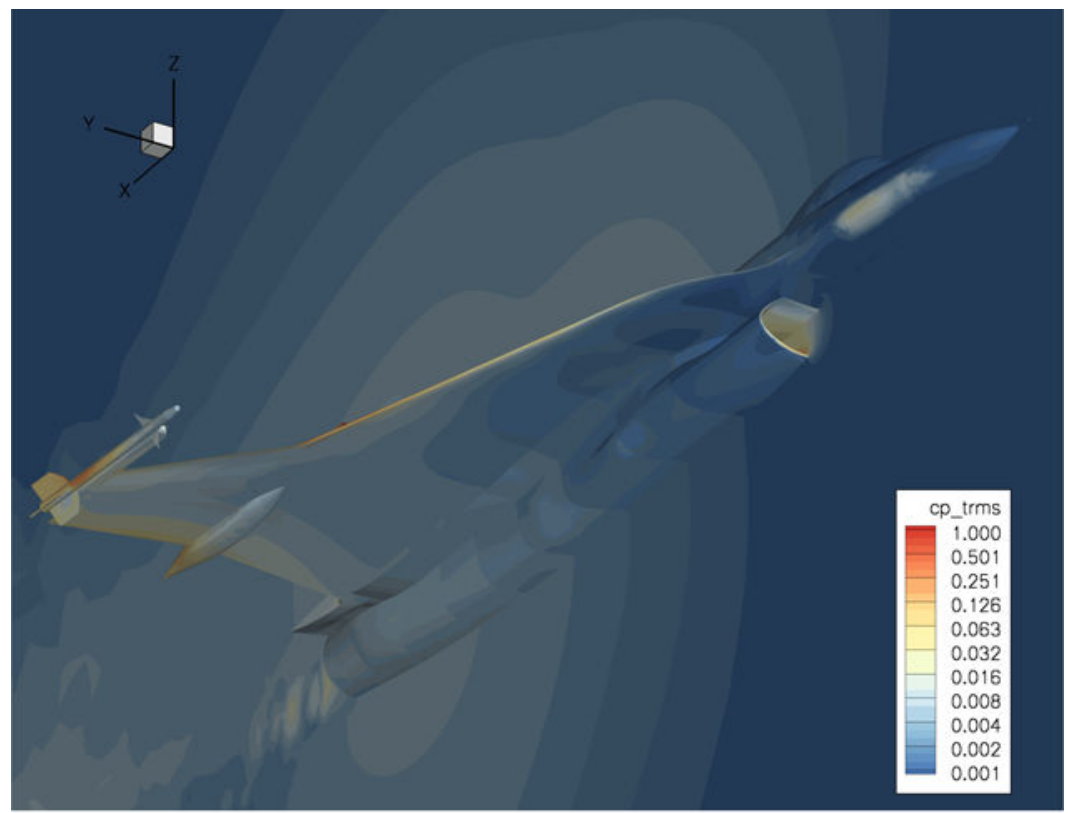

a) Medium grid, $11 \mathrm{M}$.

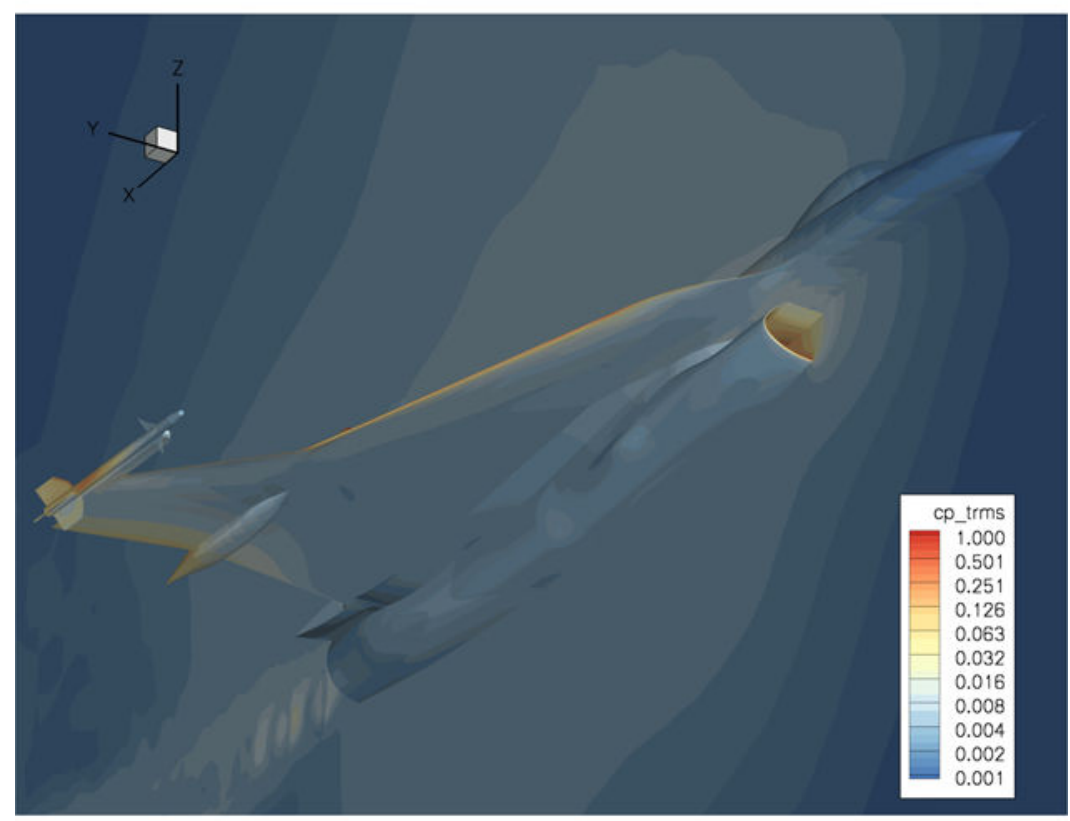

b) Fine grid, 24M.

Figure 13.

Lower surface pressure coefficient RMS variation for FUN3D MDDES. 


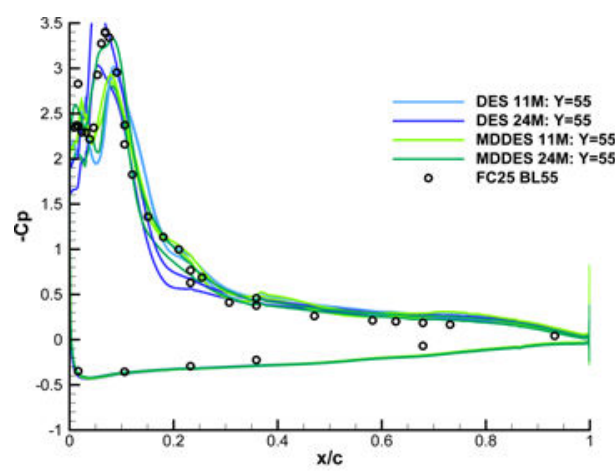

a) BL 55 .

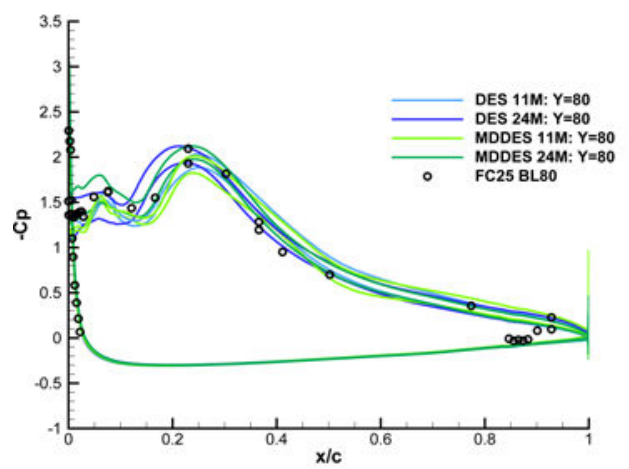

c) BL 80.

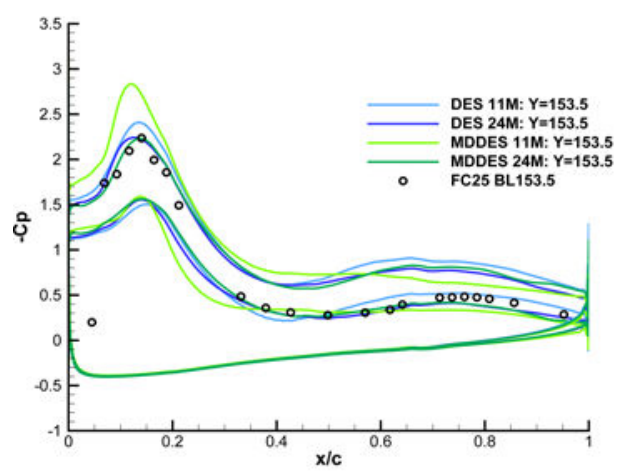

e) BL 153.5.

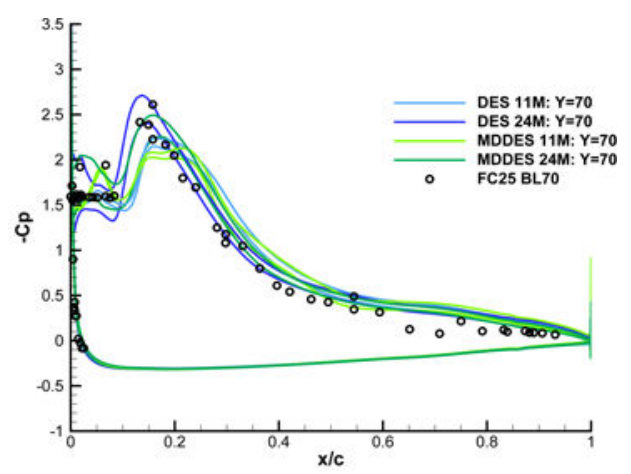

b) BL 70 .

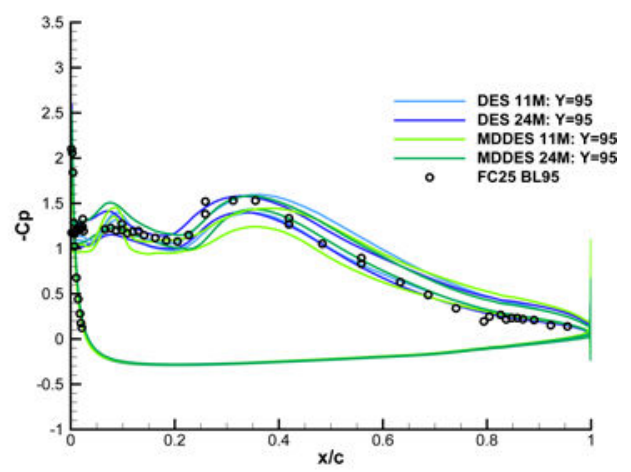

d) BL 95.

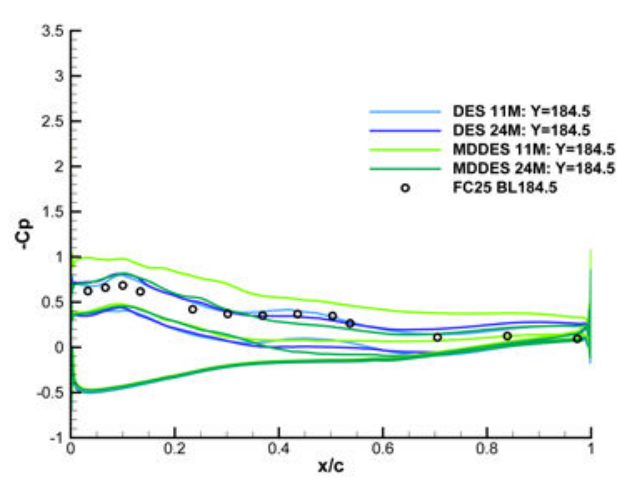

f) BL 184.5.

Figure 14.

FUN3D standard deviation of surface pressure coefficient along butt lines. 


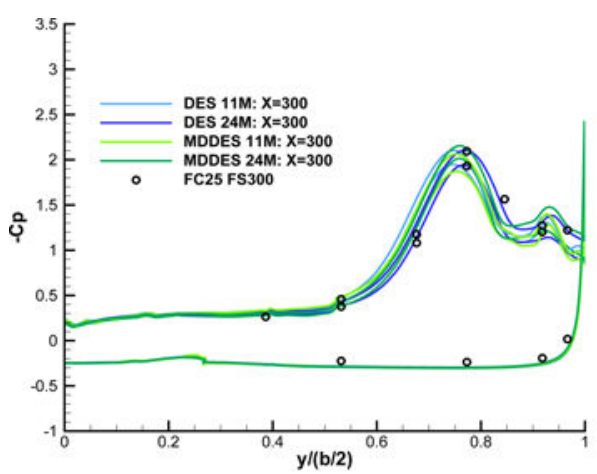

a) FS 300 .

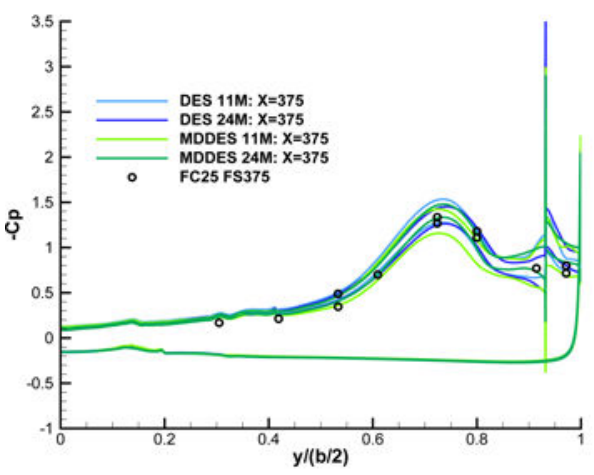

c) FS 375 .

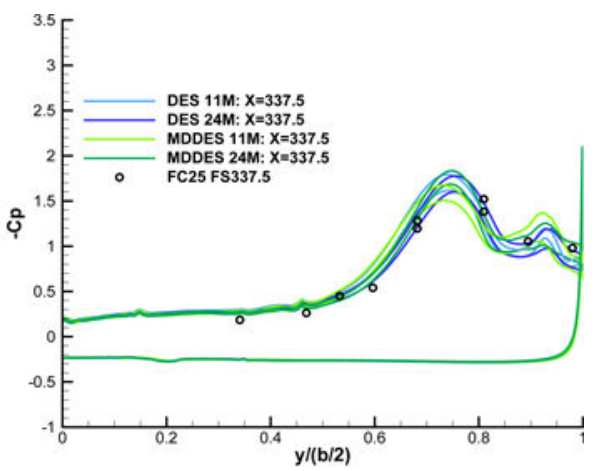

b) FS 337.5.

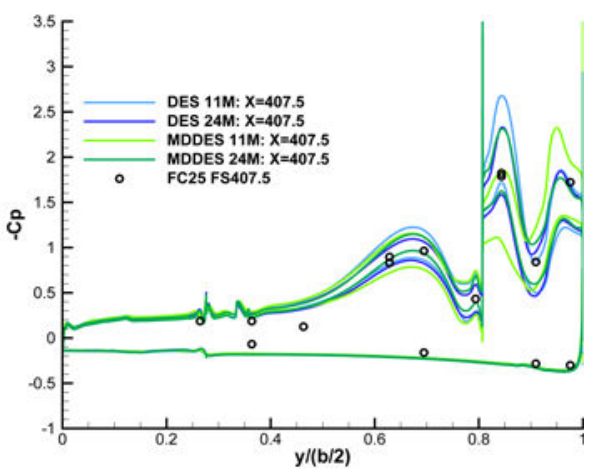

d) FS 407.5.

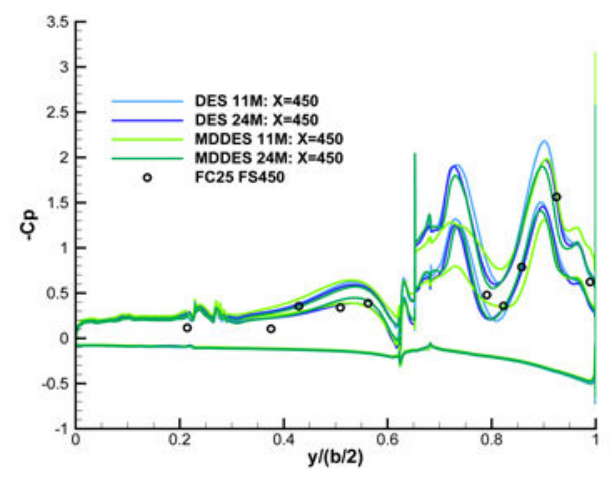

e) FS 450 .

Figure 15.

FUN3D standard deviation of surface pressure coefficient along fuselage stations. 

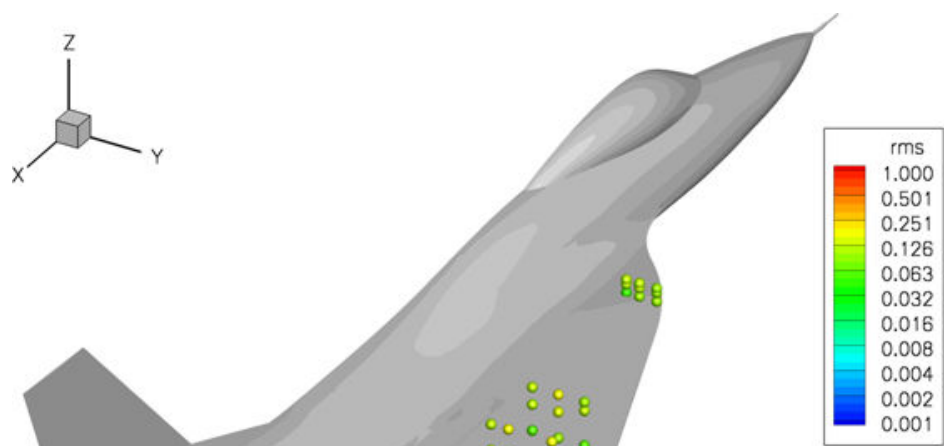

a) Large time step, $\Delta t=5$.

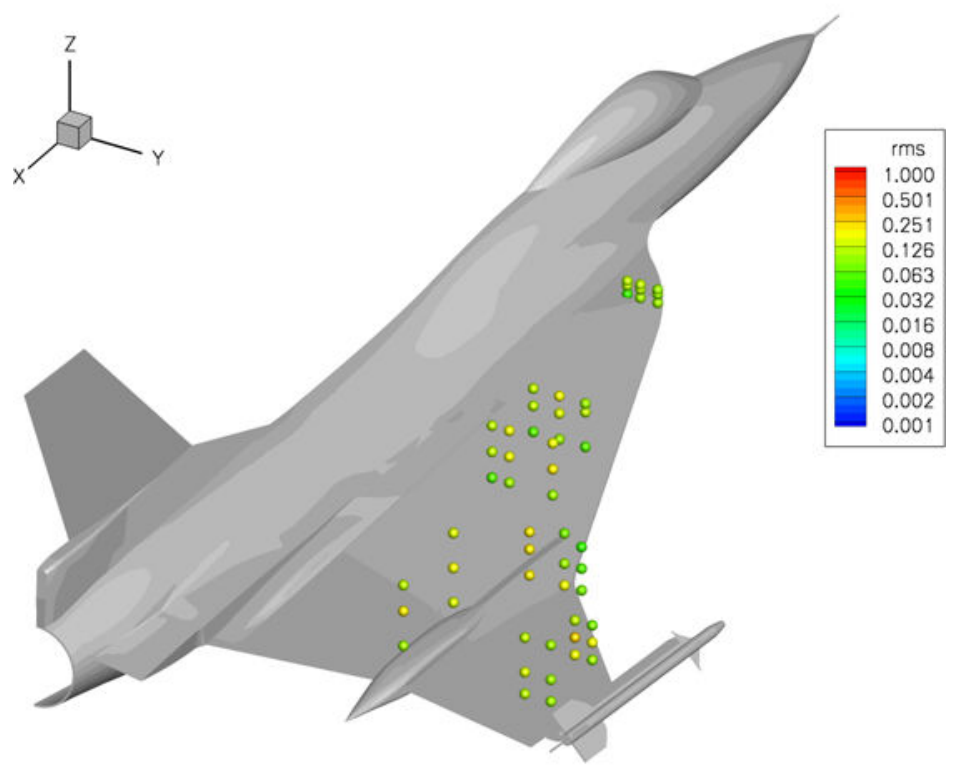

b) Small time step, $\Delta t=1$.

Figure 16.

Point pressure coefficient RMS for USM3D DES, coarse grid, 19M. 

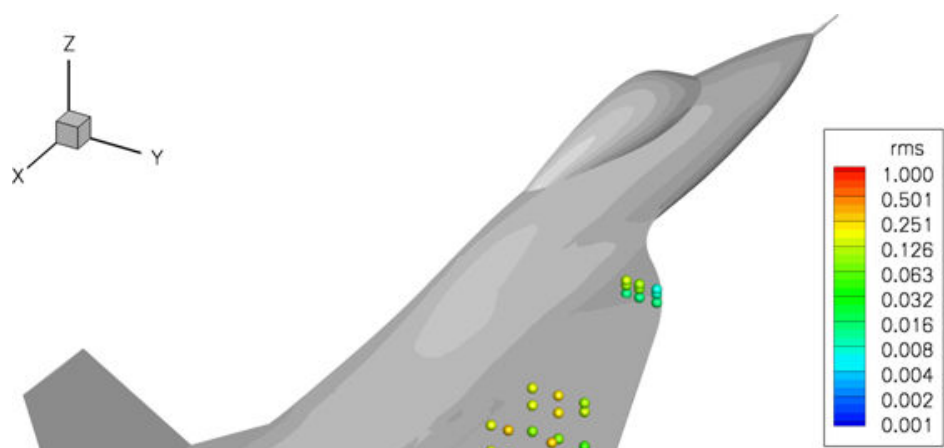

a) Medium grid, 11M.

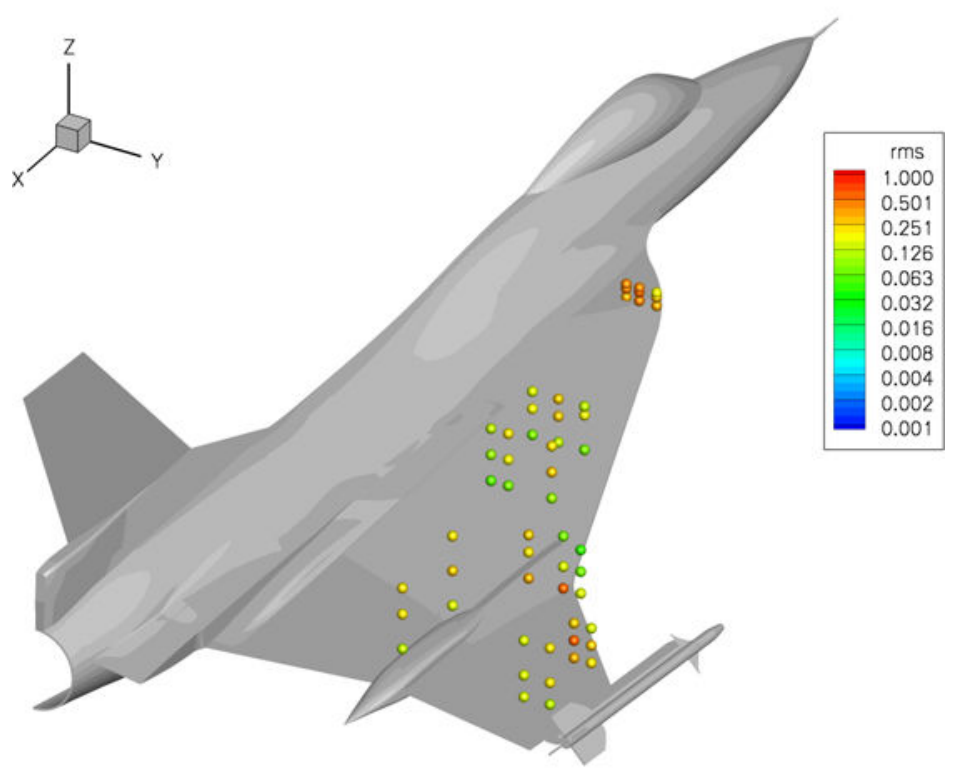

b) Fine grid, 24M.

Figure 17.

Point pressure coefficient RMS for FUN3D DES. 

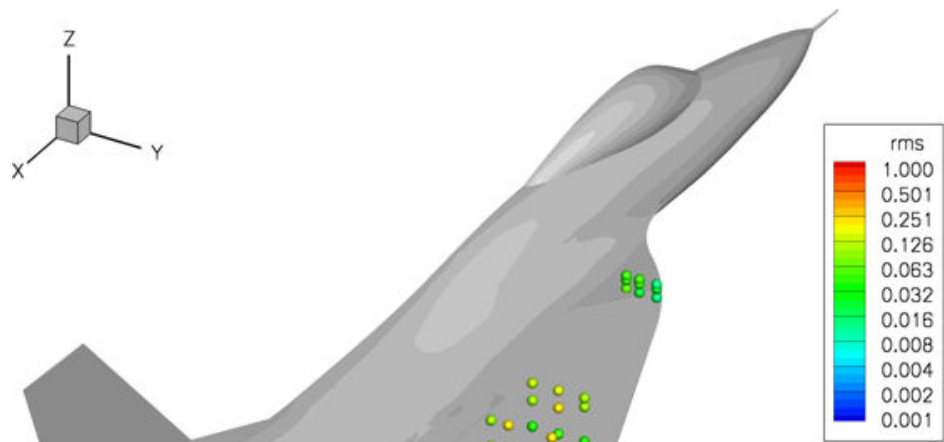

a) Medium grid, 11M.

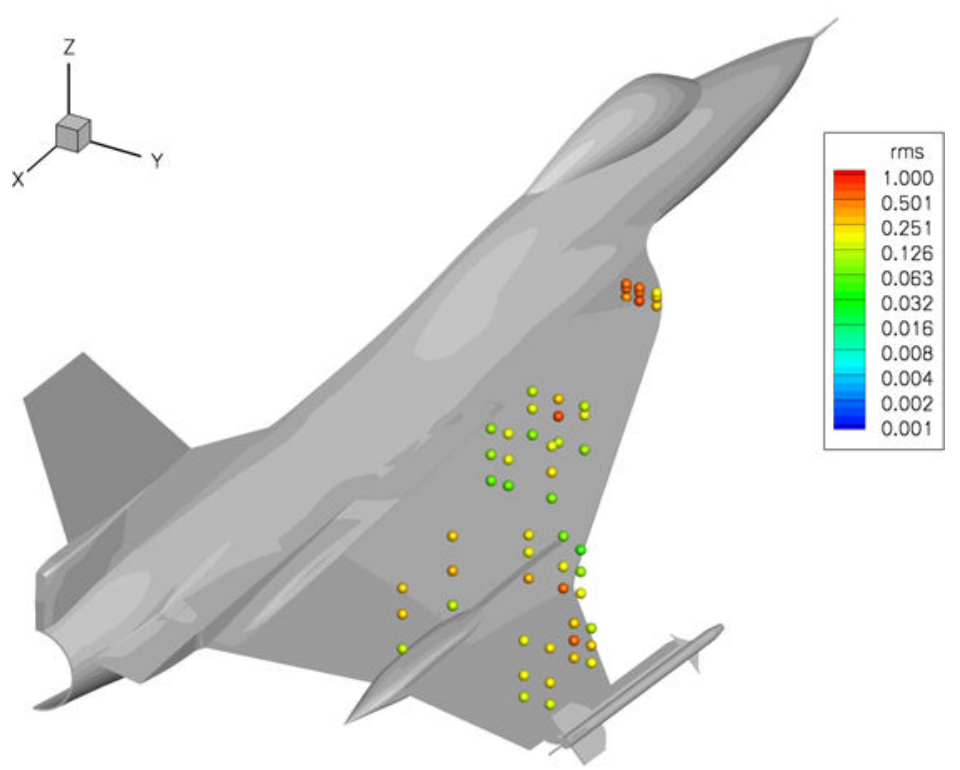

b) Fine grid, 24M.

Figure 18.

Point pressure coefficient RMS for FUN3D MDDES. 

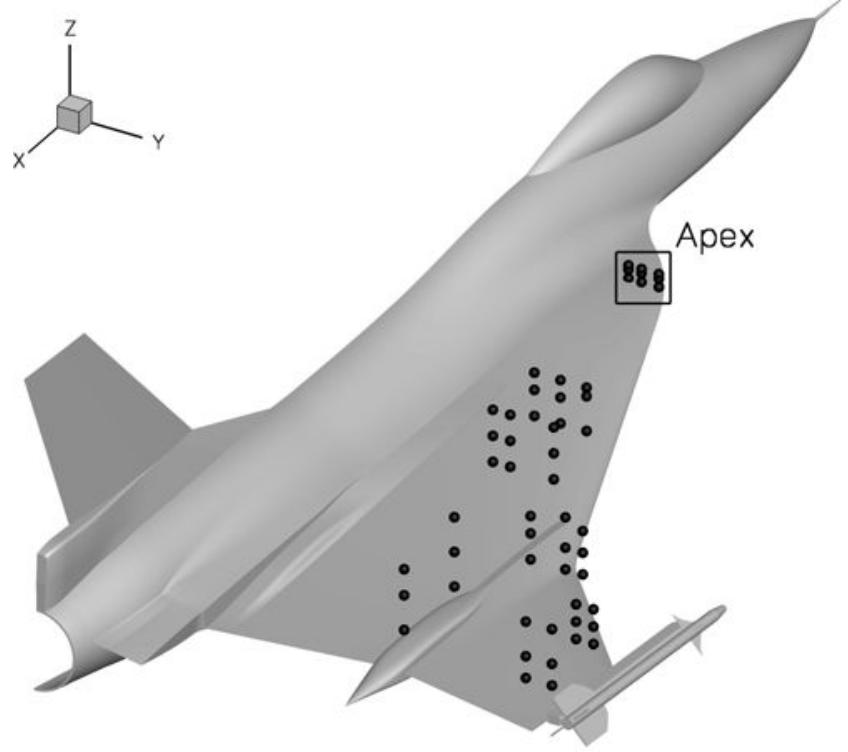

a) Apex point group.

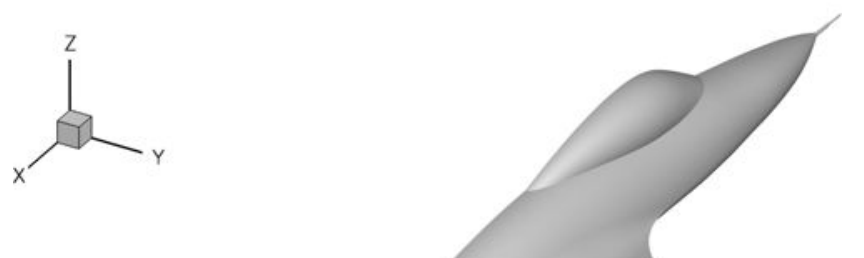

88

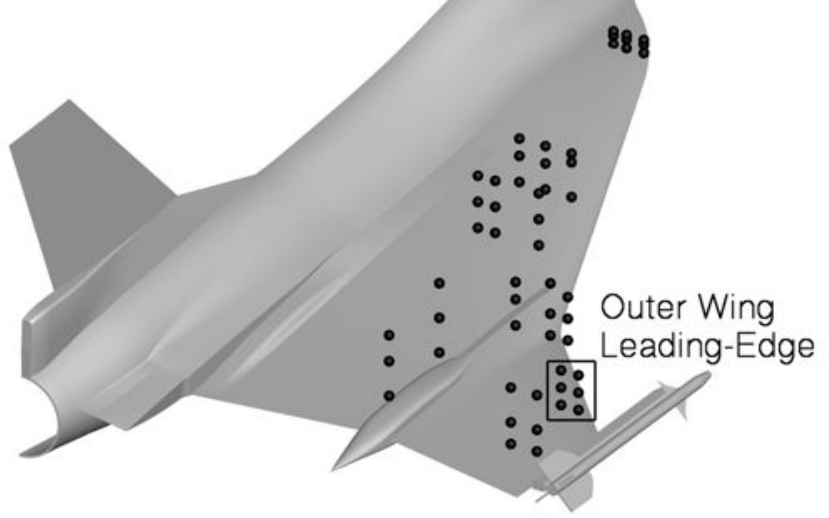

b) Outer wing leading-edge point group.

Figure 19.

Point pressure coefficient RMS groups. 


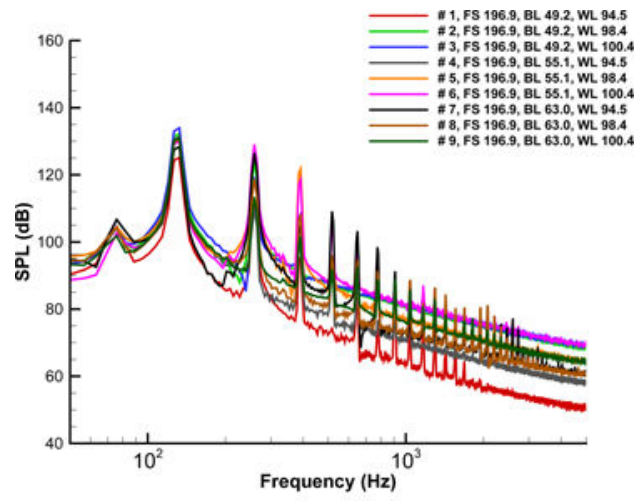

a) Coarse grid, 19M, small time step, $\Delta t=1$.

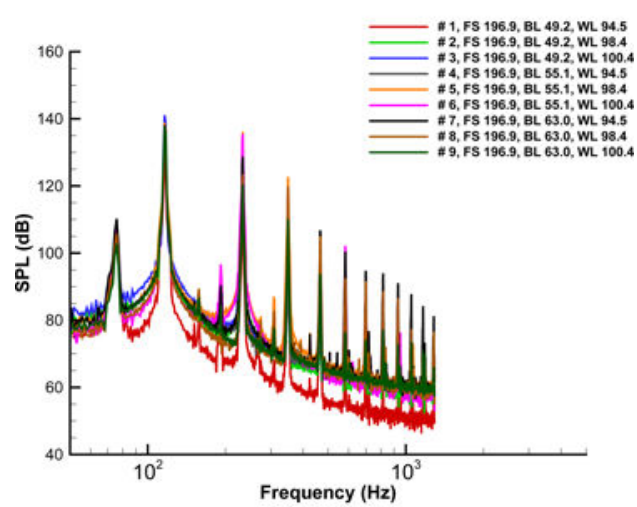

b) Coarse grid, $19 \mathrm{M}$, large time step, $\Delta t=5$.

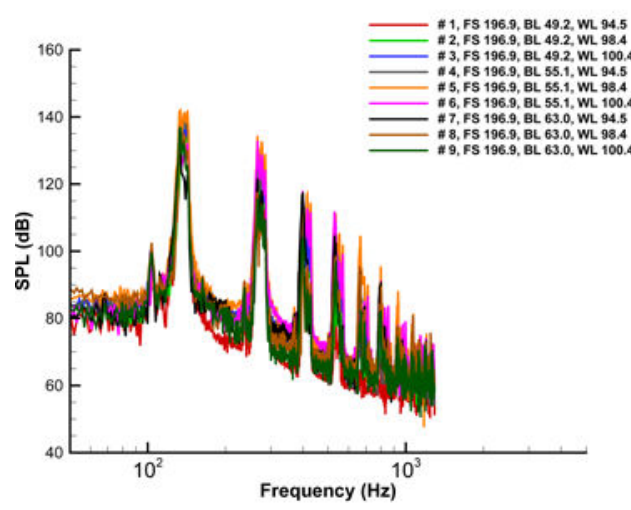

c) Medium grid, $62 \mathrm{M}$, large time step, $\Delta t=5$.

Figure 20.

Apex sound pressure level spectra for USM3D DES. 


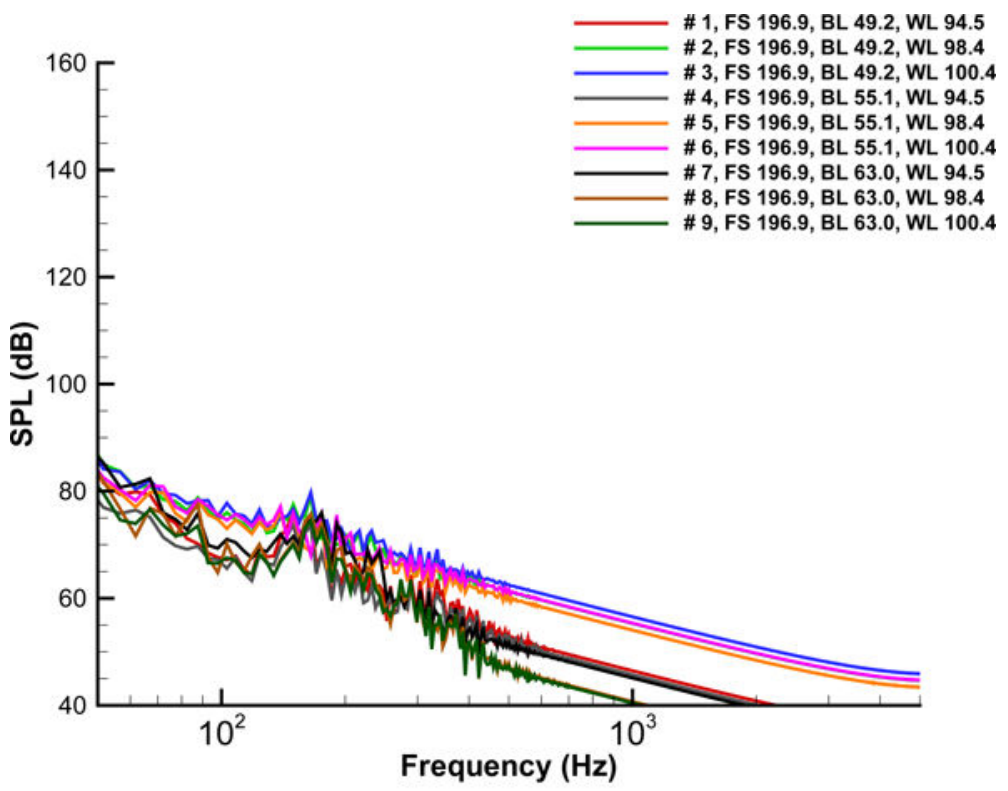

a) Medium grid, 11M.

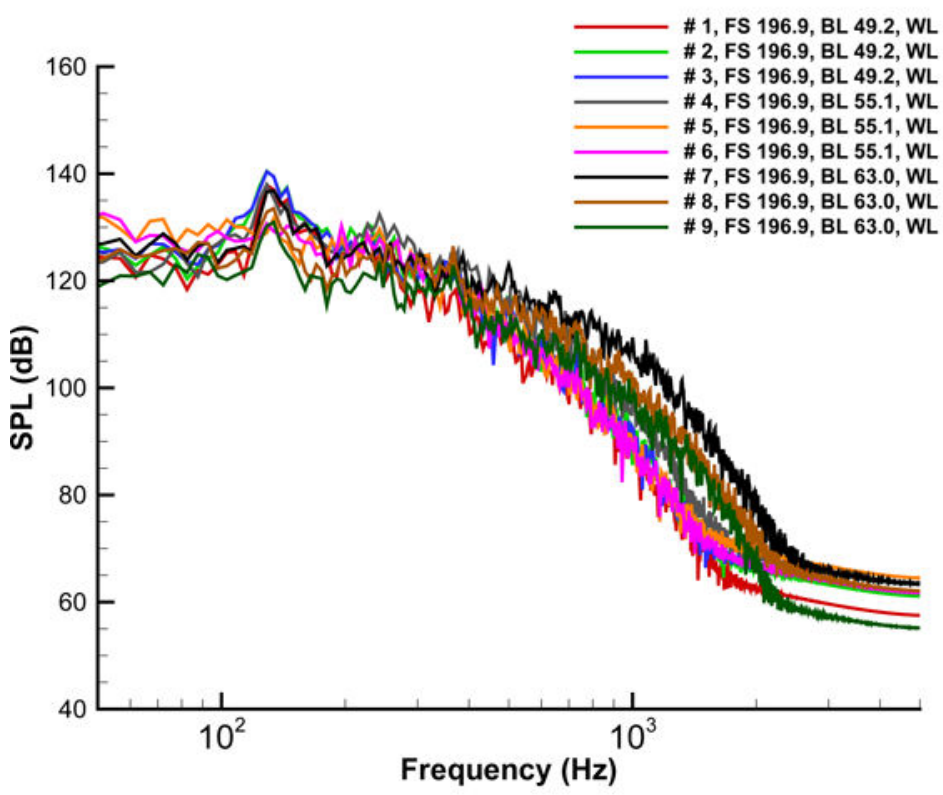

b) Fine grid, 24M.

Figure 21.

Apex sound pressure level spectra for FUN3D DES. 


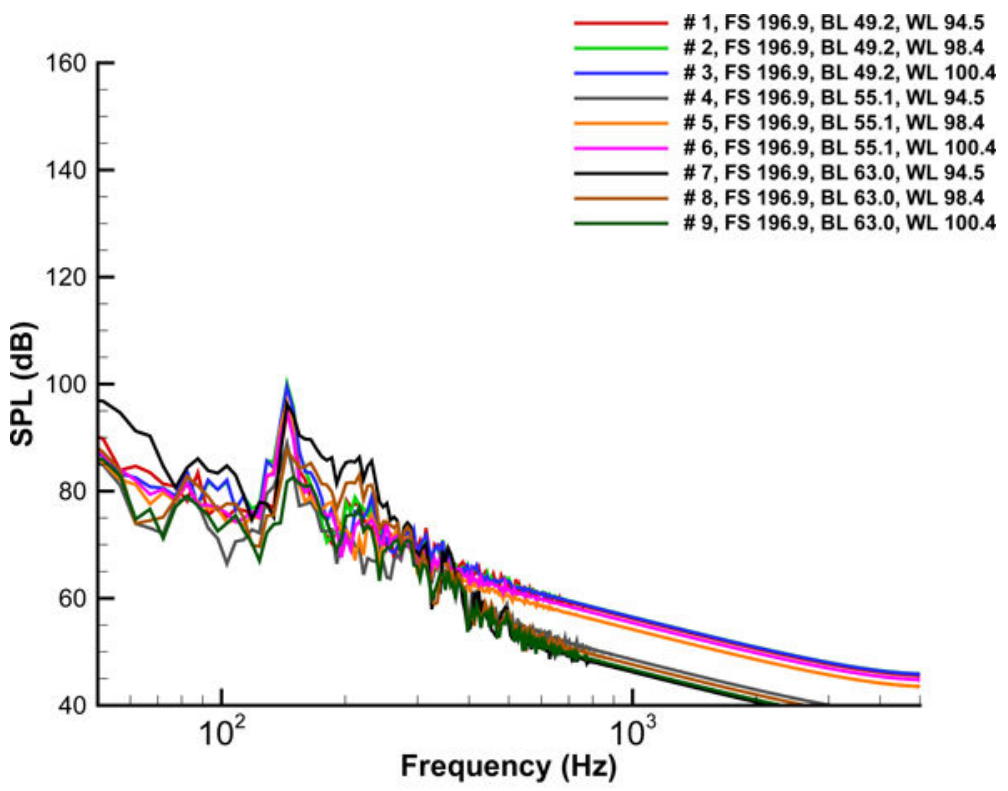

a) Medium grid, $11 \mathrm{M}$.

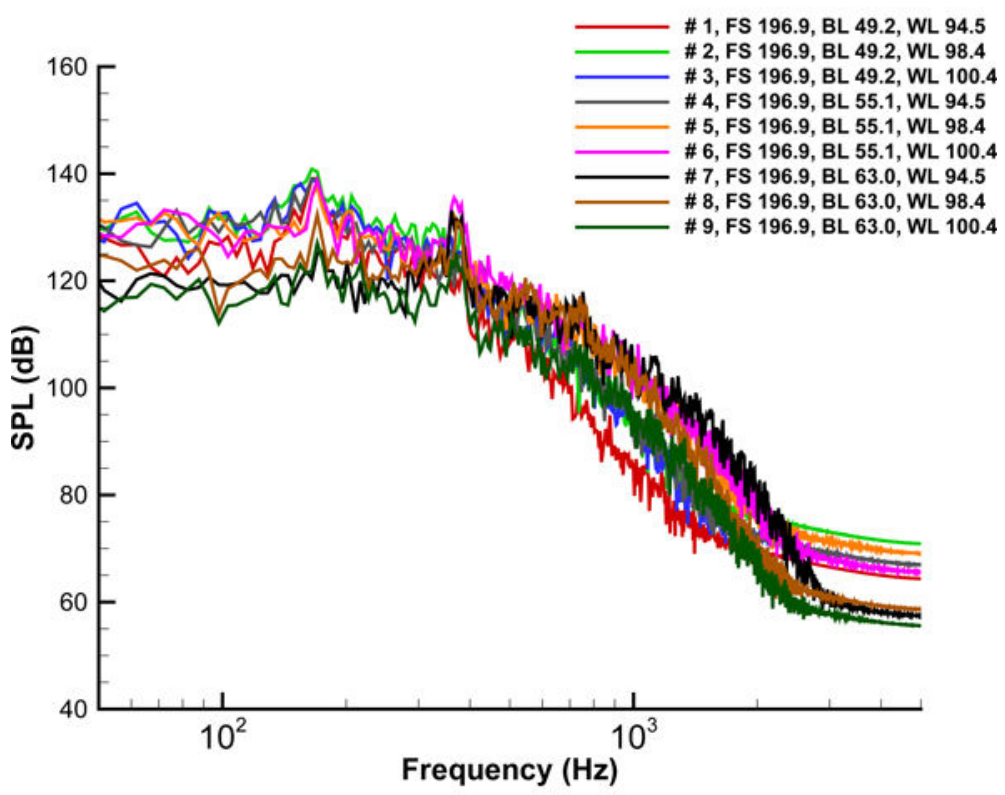

b) Fine grid, 24M.

Figure 22.

Apex sound pressure level spectra for FUN3D MDDES. 


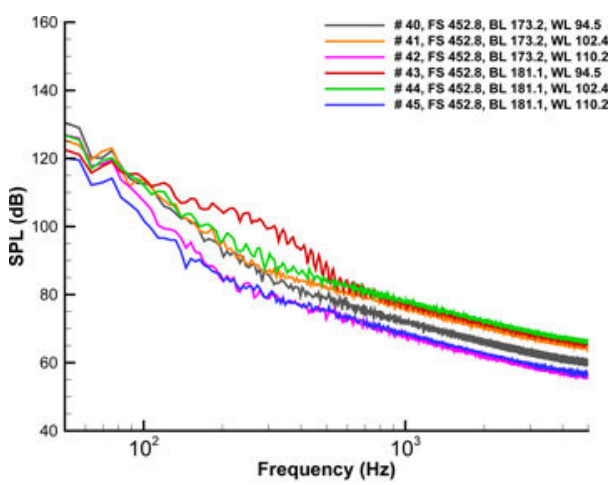

a) Coarse grid, 19M, small time step, $\Delta t=1$.

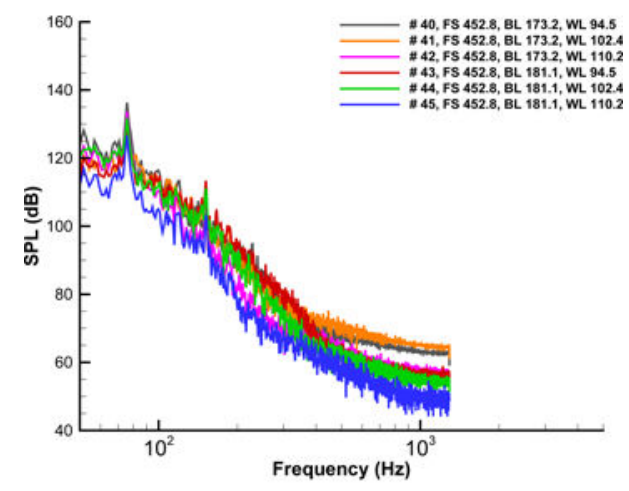

b) Coarse grid, $19 \mathrm{M}$, large time step, $\Delta t=5$.

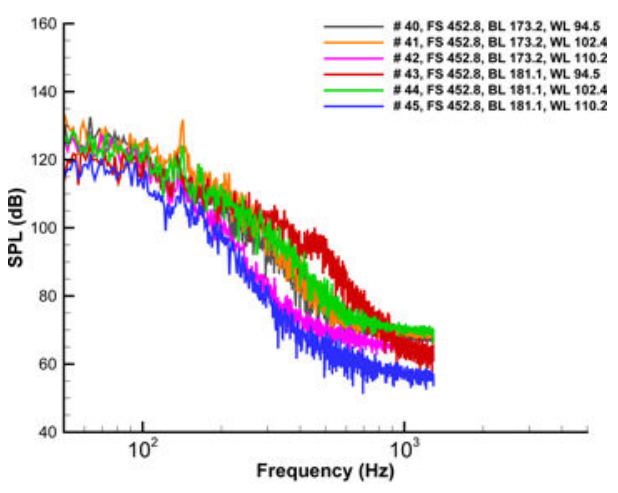

c) Medium grid, $62 \mathrm{M}$, large time step, $\Delta t=5$.

Figure 23.

Outer wing leading-edge sound pressure level spectra for USM3D DES. 


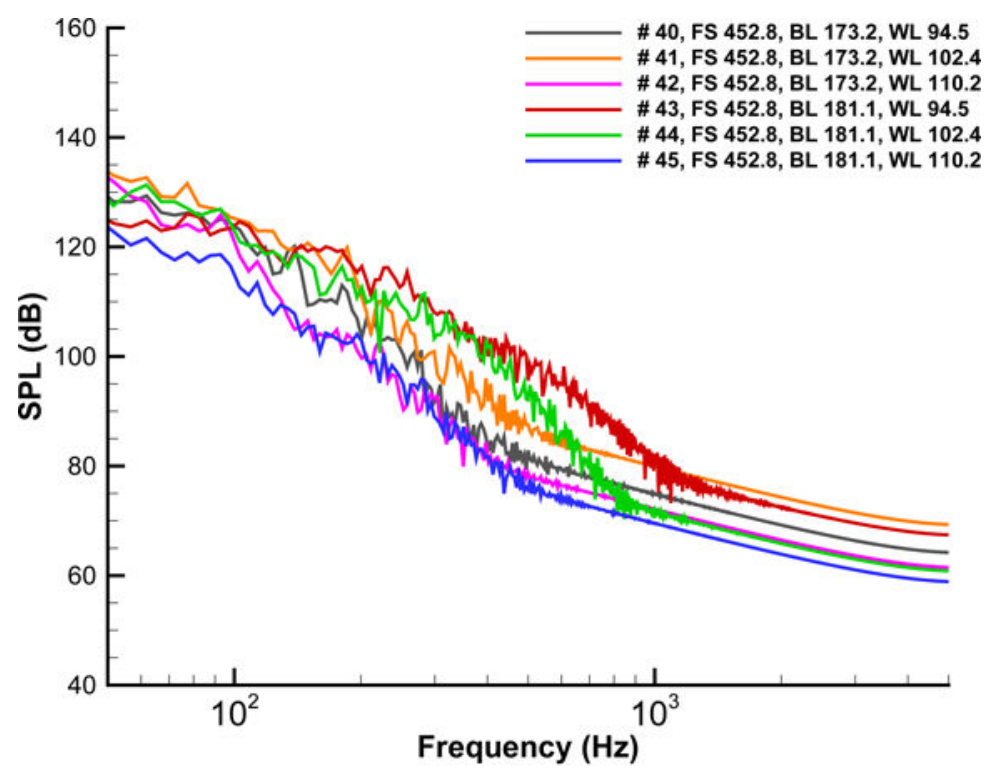

a) Medium grid, $11 \mathrm{M}$.

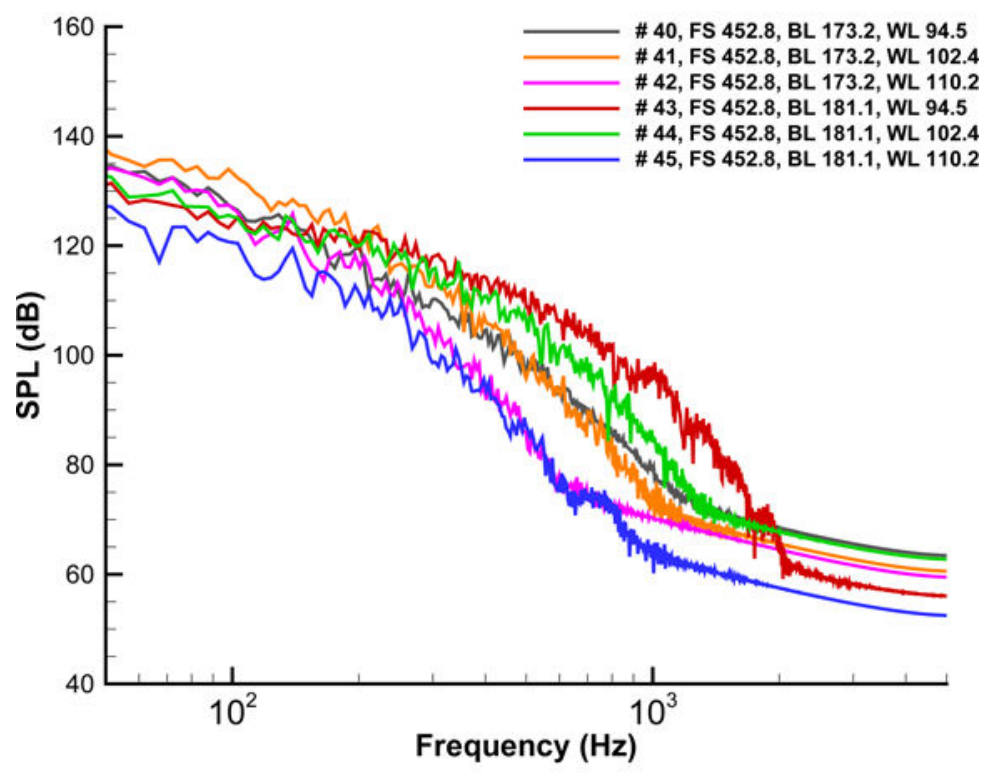

b) Fine grid, 24M.

Figure 24.

Outer wing leading-edge sound pressure level spectra for FUN3D DES. 


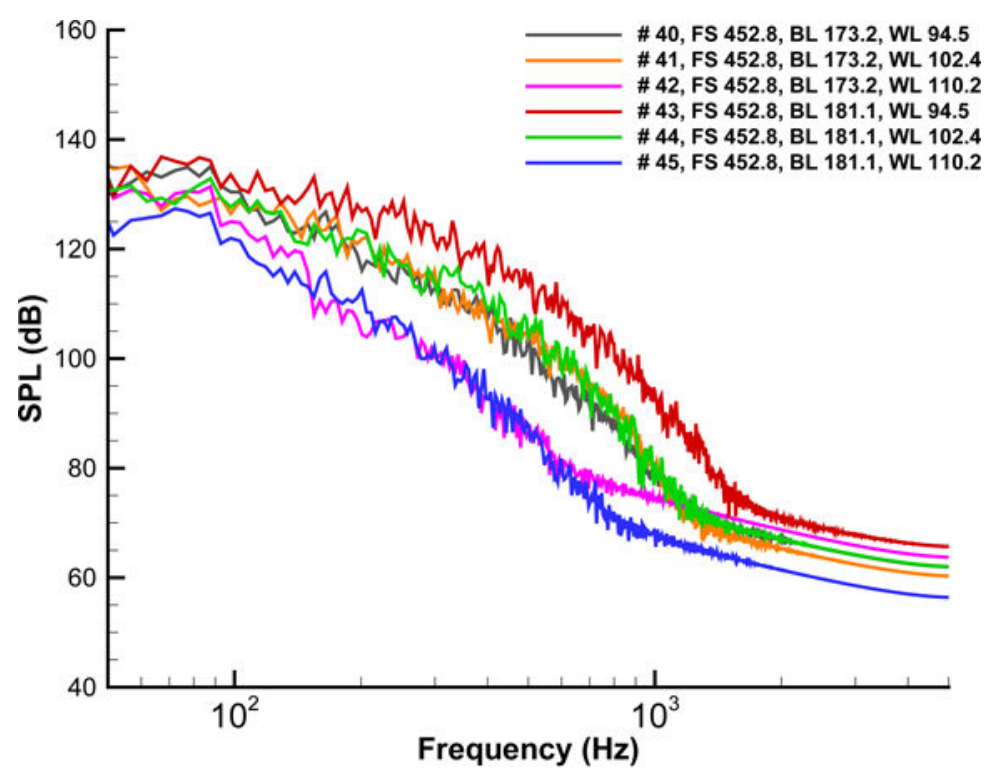

a) Medium grid, $11 \mathrm{M}$.

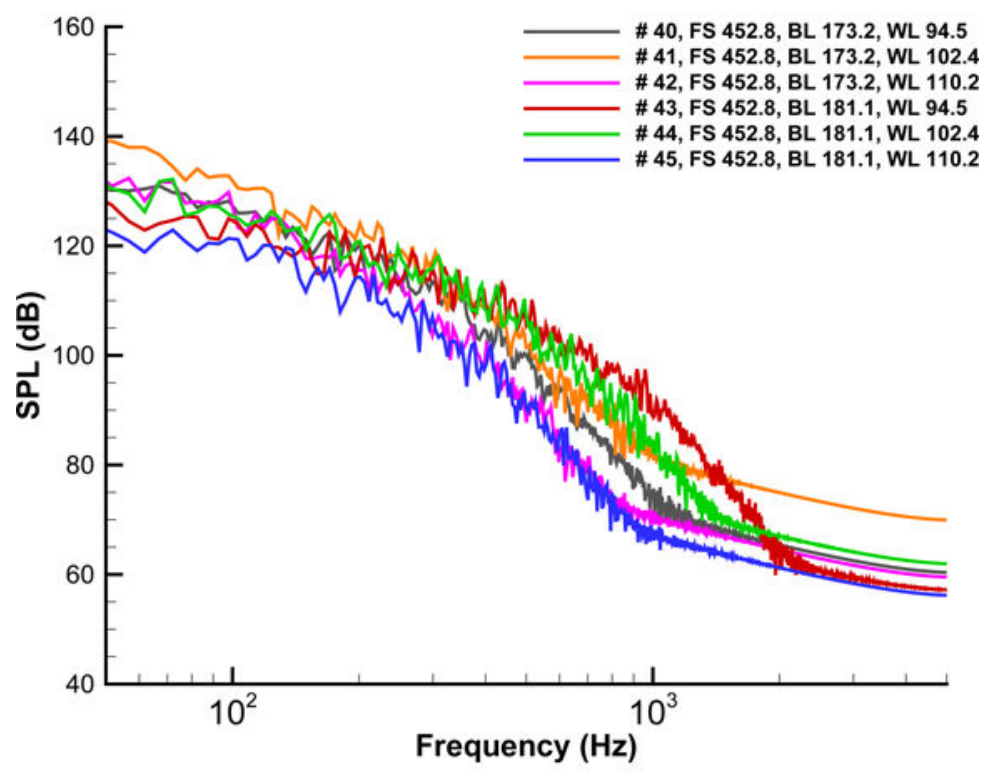

b) Fine grid, 24M.

Figure 25.

Outer wing leading-edge sound pressure level spectra for FUN3D MDDES. 


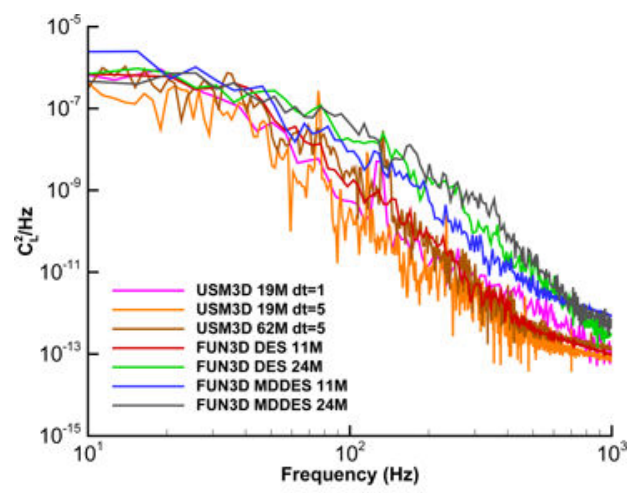

a) Lift coefficient.

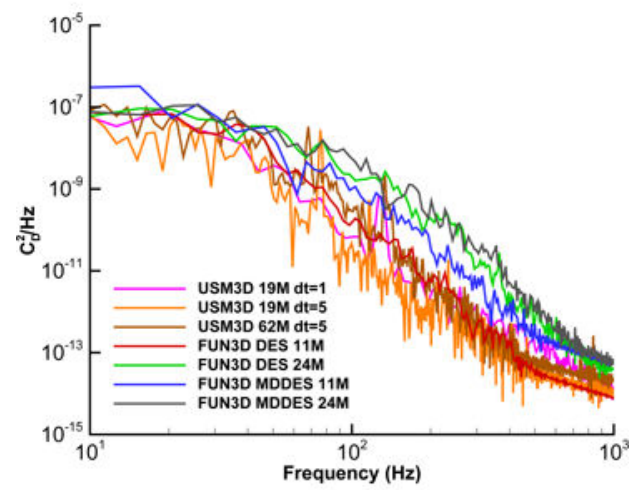

b) Drag coefficient.

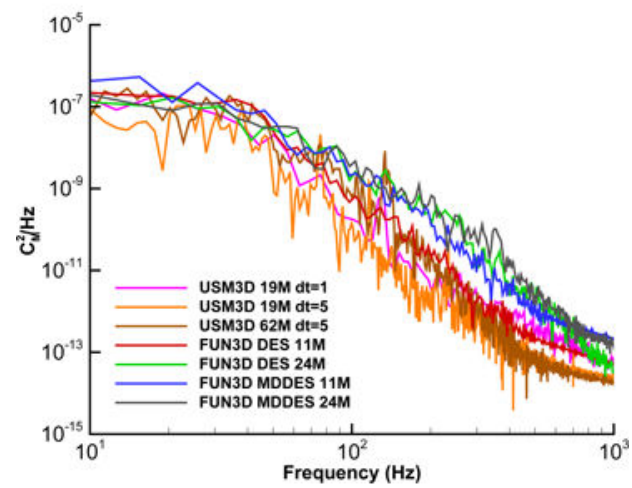

c) Pitching moment coefficient.

Figure 26.

Power spectral density of forces. 
Table 1.

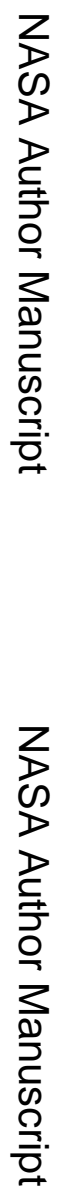

Propulsion measurements and boundary conditions.

\begin{tabular}{llll}
\hline Inlet static temperature & $470.1^{\circ} \mathrm{R}$ & & \\
Inlet Mach number & 0.447 & & \\
Inlet static pressure & $8.72 \mathrm{psia}$ & Inlet static pressure ratio & 0.86265 \\
Exit total pressure & $26.3 \mathrm{psia}$ & Exit total pressure ratio & 2.6018 \\
Exit total temperature & $1209^{\circ} \mathrm{R}$ & Exit total temperature ratio & 2.5029 \\
\hline
\end{tabular}


Table 2.

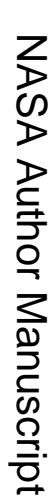

Reference geometry for the F-16XL-1. [2]

\begin{tabular}{lc}
\hline Wing Reference Area & 86,400 in. $^{2}$ \\
Mean Aerodynamic Chord & 296.4 in. \\
Wing Span & 388.8 in. \\
Aspect Ratio & 1.75 \\
\hline
\end{tabular}

Aspect Ratio 
Table 3.

Grids.

\begin{tabular}{lrrr}
\hline Description & Nodes & Tetrahedra & First cell height (in.) \\
\hline Coarse & $3,302,181$ & $19,369,037$ & 0.00092 \\
Medium & $10,635,136$ & $62,472,142$ & 0.00061 \\
Fine & $24,330,073$ & $143,034,292$ & 0.00041 \\
\hline
\end{tabular}


Table 4.

Coefficient of lift.

\begin{tabular}{lccc}
\hline Case & $C_{L}^{\text {mean }}$ & $C_{L}^{\mathrm{rms}}$ & $\left(C_{L}^{\mathrm{min}}-C_{L}^{\max }\right)$ \\
\hline WT & 0.8405 & & \\
FUN3D SA 11M & 0.8036 & & \\
FUN3D SA 24M & 0.8041 & & \\
USM3D DES 19M $\Delta t=1$ & 0.7507 & 0.0055 & $(0.7347-0.7656)$ \\
USM3D DES 19M $\Delta t=5$ & 0.7605 & 0.0037 & $(0.7503-0.7725)$ \\
FUN3D DES 11M & 0.8015 & 0.0054 & $(0.7880-0.8138)$ \\
FUN3D DES 24M & 0.8021 & 0.0058 & $(0.7868-0.8180)$ \\
FUN3D MDDES 11M & 0.7939 & 0.0088 & $(0.7688-0.8159)$ \\
FUN3D MDDES 24M & 0.8020 & 0.0054 & $(0.7870-0.8180)$ \\
\hline
\end{tabular}

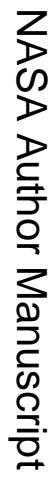

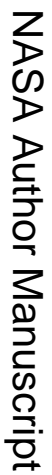


Table 5.

\begin{tabular}{|c|c|c|c|c|}
\hline \multirow{2}{*}{$\begin{array}{l}Z \\
\mathbb{D} \\
D\end{array}$} & \multicolumn{4}{|l|}{ Coefficient of drag. } \\
\hline & Case & $C_{D}^{\text {mean }}$ & $C_{D}^{\mathrm{rms}}$ & $\left(C_{D}^{\min }-C_{D}^{\max }\right)$ \\
\hline & WT & 0.2693 & & \\
\hline & FUN3D SA 11M & 0.4478 & & \\
\hline & FUN3D SA 24M & 0.4507 & & \\
\hline & USM3D DES $19 \mathrm{M} \Delta t=1$ & 0.4801 & 0.0018 & $(0.4753-0.4845)$ \\
\hline & USM3D DES $19 \mathrm{M} \Delta t=5$ & 0.4823 & 0.0012 & $(0.4791-0.4860)$ \\
\hline & FUN3D DES 11M & 0.4513 & 0.0017 & $(0.4462-0.4555)$ \\
\hline & FUN3D DES 24M & 0.4526 & 0.0020 & $(0.4476-0.4577)$ \\
\hline & FUN3D MDDES 11M & 0.4463 & 0.0030 & $(0.4375-0.4528)$ \\
\hline & FUN3D MDDES 24M & 0.4528 & 0.0020 & $(0.4472-0.4585)$ \\
\hline
\end{tabular}


Table 6.

\begin{tabular}{|c|c|c|c|c|}
\hline \multirow[b]{2}{*}{ D } & \multicolumn{4}{|c|}{ Coefficient of pitching moment. } \\
\hline & Case & $C_{M}^{\text {mean }}$ & $C_{M}^{\mathrm{rms}}$ & $\left(C_{M}^{\min }-C_{M}^{\max }\right)$ \\
\hline & WT & -0.0052 & & \\
\hline & FUN3D SA 11M & 0.0025 & & \\
\hline & FUN3D SA 24M & 0.0024 & & \\
\hline & USM3D DES $19 \mathrm{M} \Delta t=1$ & 0.0062 & 0.0034 & $(-0.0025-0.0163)$ \\
\hline & USM3D DES $19 \mathrm{M} \Delta t=5$ & 0.0072 & 0.0022 & $(-0.0002-0.0124)$ \\
\hline & FUN3D DES 11M & -0.0057 & 0.0030 & $(-0.0145-0.0013)$ \\
\hline & FUN3D DES 24M & -0.0037 & 0.0026 & $(-0.0115-0.0022)$ \\
\hline & FUN3D MDDES $11 \mathrm{M}$ & -0.0021 & 0.0041 & $(-0.0121-0.0090)$ \\
\hline & FUN3D MDDES 24M & -0.0021 & 0.0025 & $(-0.0108-0.0044)$ \\
\hline
\end{tabular}

